\title{
TRANSCRIPCIÓN PALEOGRÁFICA
}

\{h. 228\} [margen superior: e] [margen superior: signo cruz] [impreso: vnquartillo] [sello] [impreso: SELLO QVARTO VN QVARTILLO | AÑOS DE MIL Y SEISCIENTOS Y SE|TENTA Y DOS Y SETENTA Y TRES] [sello: PARA LOS AÑOS DE | 1674 Y 1675] [sello] [impreso: PARA LOS AÑOS DE | 16841685 Y 1686]

[margen subrayado: Auto] $\{1\}$ Enlauilla deguancauelica $\{2\}$ endiez y seis dias del mes de $\{3\}$ Abrill demill y seiscientos YO $\{4\}$ chenttaY seis años el Señor $\{5\}$ Docttor Don Juan Luis $\{6\}$ Lopez del consejo de su magestad $\{7\}$ Su Alcalde de cortte mas an $\{8\}$ tiguo dela Real audiencia delos $\{9\}$ Reyes governador de esta $\mathrm{d}<\mathrm{ic}>$ hauilla $\mathrm{Su}$ $\{10\}$ çerro y mina rreal de Acogue Correxi $\{11\}$ dor y Justicia mayor dela Prouinçia $\{12\}$ de los Angaraes Alcalde mayor $\{13\}$ de Minas y teniente decapittan general $\{14\}$ En sus distritos, dijo quepor quanto El $\{15\}$ ex<celentisimo> Señor Duque dela Palata prin $\{16\}$ cipe de Masa Virrey Y capitan general $\{17\}$ deestos rreynos Con carta de siette del $\{18\}$ Corriente arremitido a su merçed vn $\{19\}$ testimonio de autos hechos porel Doctor $\{20\}$ Don Melchor de cotes Peralta Cura de $\{21\}$ Conayca en laprouinçia de Angaraes $\{22\}$ Sobre el vino que ha rrepartido a los $\{23\}$ Yndios de aquel Repartimientto $\{24\}$ El capittan Don Juan flores de $\{25\}$ Valdes theniente General dela $\{26\} \mathrm{d}<\mathrm{ic}>$ ha Prouincia de Angaraes para $\{27\}$ que boluiendo aexaminar los $\{\mathrm{h} .228 \mathrm{v}\}$ [margen superior: $\mathrm{e}]\{1\}$ testigos que dijeron en $\mathrm{d}<\mathrm{ic}>$ ha Causa $\mathrm{U}$, otros $\{2\}$ que sepan del caso le castigue y condene $\{3\}$ en perdimiento de lo que Ymporta $\{4\}$ re por ser contra Ordenes y lei rre $\{5\}$ copilada y para sauer y abriguar $\{6\}$ lo que en esto apasado mandaba Y $\{7\}$ mando haçer estacabeza deproçesso $\{8\}$ Y que conella Se ponga Vn tantto dela $\{9\} \mathrm{d}<\mathrm{ic}>$ ha cartta de $\mathrm{s}<\mathrm{u}>\mathrm{e}<\mathrm{x}$ celencia $>$ y el testimonio de $\mathrm{d}<\mathrm{ic}>$ hos $\{10\}$ auttos deque en ella se haçe mençion $\{11\}$ que embia apedir al $\mathrm{d}<\mathrm{ic}>\mathrm{ho} \mathrm{D}<$ octor $>$ $\mathrm{D}<\mathrm{on}>$ Melchor $\{12\}$ Cottes deperalta los Originales y por $\{13\}$ Su tenor Se exsaminen y rratifiquen $\{14\}$ los ttestigos que se hallare a ver dicho $\{15\}$ en $\mathrm{d}<\mathrm{ic}>$ ha causa para lo qual conparescan $\{16\}$ en esttauilla antte su merçed y sepase $\{17\}$ a las demas diligencias que combiniere $\{18\}$ Y fuere Neçesario y asi lo proueyo $\operatorname{man}\{19\}$ do $\mathrm{Y}$ firmo $=$ Don Juan luis Lopez $=\{20\}$ Antte mi Miguel de cantoral escruia $\{21\}$ no de su Magesttad

\{22\} [margen: Cartta | desuex<celencia>] El Docttor Don melchor de cotes depe $\{23\}$ raltta Cura de conaica en la jurisdicion $\{24\}$ de Angaraes medaquentta deque a $\{25\}$ uiendo ydo al asiento de acobamba $\{26\}$ Y a Otros anexos desu Venefiçio $\{27\}$ no an podido muchos Yndios cum $\{28\}$ plir Con la Ygleçia por Venir $\{29\}$ embriagados auiendo Ocasionado $\{30\}$ estto Don Ju<an> flores de Valdes $\{$ h. 229\} [margen superior: e] $\{1\}$ tenientte general de aquel partido $\{2\}$ por auer Repartido vino y bendidose $\{3\}$ por su quentta sobre que le hizo Causa $\{4\}$ Cuios auttos me rremite deque di $\{5\}$ Vistta al Señor fiscal y Con su rres $\{6\}$ puestta he rresuelto emuiar a $\mathrm{V}<$ uestra> $\mathrm{M}<$ erced $>\{7\}$ Esttos auttos Sobre el vino que arre $\{8\}$ partido a los Yndios Don Juan $\{9\}$ flores de Valdes teniente de anga $\{10\}$ raes para que boluiendo 
aexsami $\{11\}$ nar los testigos que disen En esta $\{12\}$ Causa $U$ otros que sepan del caso $\{13\}$ le castigue $\mathrm{Y}$ condene en perdim<iento> $\{14\}$ de lo que Ymportare por ser Con $\{15\}$ tra Ordenes Y ley rrecopilada y de $\{15\}$ lo que rresulttare me daraquenta $\{16\}$ $\mathrm{V}<$ uestra> $\mathrm{M}<$ erced> aquien Guarde Dios muchos $\{17\}$ años Lima $\mathrm{Y}$ abrill Siette demill $\{18\}$ Y seisçienttos $\mathrm{Y}$ ochentaY seis = El $\{19\}$ Duque dela Palatta = Señor Go $\{20\}$ vernador Don Juan Luis Lopez \{21\} Concuerda Con su Orijinal aqueme $\{22\}$ rrefiero $=\mathrm{Y}$ en fee deello fize mi $\{23\}$ signo, en testimonio de Verdad $\{24\}$ Miguel de cantoral Escriuano \{25\} desu Magesttad

\{26\} [margen subrayado: Cauessa | deProseso] En el asientto de San Joseph de aco $\{27\}$ bamba dela jurisdicion delapro $\{28\}$ vinçia delos Angaraes en veinte $\{h .229 \mathrm{v}\}$ [margen superior: e] $\{1\}$ testigos que dijeron en $\mathrm{d}<\mathrm{ic}>$ ha Causa $\mathrm{U}$, otros $\{2\}$ que sepan del caso le castigue y condene $\{3\}$ en perdimiento de lo que Ympor $\{4\}$ tare por ser contra Ordenes y lei rre $\{5\}$ copilada y para sauer y abriguar $\{6\}$ lo que en esto apasado mandaba Y $\{7\}$ mando hacer estacabeza deprocesso $\{8\}$ Y que conella Se ponga Vn ttanto dela $\{9\} \mathrm{d}<\mathrm{ic}>$ ha Cartta de $\mathrm{s}<\mathrm{u}>\mathrm{e}<\mathrm{xcelencia}>$ y el testimonio de $\mathrm{d}<\mathrm{ic}>\mathrm{hos}\{10\}$ auttos deque en ella se haçe mencion $\{11\}$ y se embia apedir al $d<i c>$ ho $D<$ octor $>$, $\mathrm{D}<$ on> Melchor $\{12\}$ Cottes deperalta los Originales y por $\{13\} \mathrm{Su}$ ttenor Se exsaminen y rratifiquen $\{14\}$ los testigos que se hallare aber dicho $\{15\}$ en $d<i c>h a$ causa para lo qual conparescan $\{16\}$ en estauilla antte su merçed y sepase $\{17\}$ a las demas diligencias que combiniere $\{18\}$ Y fuere Necesario y asi lo proueyo $\operatorname{man}\{19\}$ do Y firmo $=$ Don Juan luis Lopez $=\{20\}$ Antte mi Miguel de cantoral escruia $\{21\}$ no de su Magesttad

\{22\} [margen: Cartta | desuex<celencia>] El Docttor Don melchor de cotes depe $\{23\}$ raltta Cura de conaica en la jurisdicion $\{24\}$ de Angaraes medaquentta deque a $\{25\}$ uiendo ydo al asiento de acobamba $\{26\}$ Y a Otros anexos desu Veneficio $\{27\}$ No an podido muchos Yndios cum \{28\}plir Con la Ygleçia por Venir \{29\} embriagados auiendo Ocasionado $\{30\}$ estto Don $\mathrm{Ju}<\mathrm{an}>$ flores de Valdes $\{\mathrm{h} .230\}$ [margen superior: e] $\{1\}$ tenientte general de aquel partido $\{2\}$ porauer Repartido, vino y bendidose $\{3\}$ por su quentta sobre que le hizo Causa $\{4\}$ Cuios auttos me rremite deque di $\{5\}$ Vistta al Señor fiscal y Con su rres $\{6\}$ puestta he rresuelto emuiar a $\mathrm{V}<$ uestra> $\mathrm{m}<$ erced $>\{7\}$ Esttos auttos Sobre el vino que arre $\{8\}$ partido a los Yndios Don Juan $\{9\}$ flores de Valdes teniente de anga $\{10\}$ raes para que boluiendo a exami $\{11\}$ nar los testigos que disen En esta $\{12\}$ Causa $U$ otros que sepan del caso $\{13\}$ le castigue $\mathrm{Y}$ condene en perdim<iento>, $\{14\}$ de lo que Ymportare por ser Con $\{15\}$ tra Ordenes Y ley rrecopilada y de $\{16\}$ lo que rresulttare me daraquenta $\{17\}$ $\mathrm{V}<$ uestra> $\mathrm{m}<$ erced>, aquien Guarde Dios muchos $\{18\}$ años lima $\mathrm{Y}$ abrill Siette demill $\{19\}$ Y seiscienttos $\mathrm{Y}$ ochenta $\mathrm{Y}$ seis $=\mathrm{El}\{20\}$ Duque dela Palatta = Señor Go $\{21\}$ vernador Don Juan Luis Lopez $\{22\}$ Concuerda Con su Orijinal aqueme $\{23\}$ rrefiero $=\mathrm{Y}$ en fee deello fize mi $\{24\}$ signo, en testimonio de Verdad $-\{25\}$ Miguel de cantoral Escriuano \{26\} desu Magesttad

\{27\} [margen subrayado: Cauessa | deProseso] En el asientto de San Joseph de aco $\{28\}$ bamba dela jurisdicion delapro $\{29\}$ vincia delos Angaraes en veinte $\{$ h. $230 \mathrm{v}\}$ 
[margen superior: e] $\{1\} \mathrm{Y}$ vndias del mes de febrero demill $\{2\}$ y seisçienttos $\mathrm{Y}$ ochentay Seis años $=\{3\}$ El Docttor Don Melchor Cottes depe $\{4\}$ raltta Curay Vicario dela Doctrina $\{5\}$ deconaica $=$ Digo que por quantto $\{6\}$ e Venido aestte $\mathrm{d}<\mathrm{ic}>$ ho asiento por ser $\{7\}$ Anexo al $d<i c>$ ho mi curato aconfesarlos $\{8\}$ Yndios que ay en el porestar tan proxima $\{9\}$ la quaresma adonde tube notiçia auia $\{10\}$ embiado Don $\mathrm{Ju}<\mathrm{an}>$ flores de Valdes $\{11\}$ tenientte general de esta $\mathrm{d}<\mathrm{ic}>$ ha Pro $\{12\}$ vinçia dos odres llenos devino para $\{13\}$ que Sevendiesen por su quenta por $\{14\}$ mano de tomas Luis Yndio alcalde $\{15\}$ del campo deque en Otras Ocaçiones $\{16\}$ que lo an traydo an rresultado $\{17\}$ Entre los Yndios pendençias y Sa\{18\}lido algunos heridos $\mathrm{Y}$ aorapo $\{19\}$ dian Suçeder muchos disgustos por $\{20\}$ ser $d<i c>$ ho Vino traido en odres Contra $\{21\}$ Viniendo alas Ordenanças y pro\{22\}uiçiones del rreal gouierno Y $\{23\}$ para obrar esttos escandalos ta quies $\{24\}$ Y borracheras Como tal cura y Vica $\{25\}$ rio Valiendome de la facultad que $\{26\}$ Seme conçede porla prouicion des $\{27\}$ pachada por el ex<celentisimo> Señor $\{28\}$ Duque dela palata Virrey $\{29\}$ de esttos rreynos. Su fecha deveinte $\{30\}$ de febrero del año pasado de seis<cientos $>\{$ h. 230\} [margen superior: e] $\{1\}$ Y ochenttaY quatro para que los Curas $\{2\}$ puedan actuar Contra los Juezes Ordi\{3\}narios hiçe esta Cauesa deproseso para $\{4\}$ quepor su tenor Se exsaminen los tes $\{5\}$ tigos que supieren del caso por Conbenir $\{6\}$ assi al Seruiçio de Ambas magesta $\{7\}$ des y por que son Yndios los que an $\{8\}$ de declarar Se nombrara Ynterprete $\{9\}$ Para ello Y asi lo probey ante mi juri $\{10\}$ dicamentte a falta denotario Siendo $\{11\}$ testigos Juan de los rrios y Diego de $\{12\}$ Segouia que lo firmaron Conmigo $\{13\}$ Docttor Don Melchor decotes Peralta $\{14\}$ Diego de segouia Juan delos Rios

\{15\} [margen subrayado: Nombra|mientto | de Ynter|prette] En el [tachado: pueblo] asiento de San Joseph $\{16\}$ de Acobamba en $d<i c>$ ho dia Veintey vno $\{17\}$ de febrero demill seisçientos y ochen $\{18\}$ tta $Y$ seis años el Doctor Don Melchor $\{19\}$ de cottes Peralta Cura Y Vicario $\{20\}$ del Venefiçio deconaica enlaprouinçia $\{21\}$ de Angaraes = Digo quepara pro\{22\}Seguir En esta causa es necesario \{23\} Nombrar Ynterprete por ser $Y n<$ dios $>\{24\}$ los que an de declarar enella y para $\{25\}$ ello nombro aMatheo de Segouia per\{26\}SonaYnteligente En la lengua de $\{27\}$ los naturales y estando presentte $\{28\}$ el susod $<$ ic $>$ ho asetto $d<i c>$ ho nombramiento $\{29\}$ Y juro a Dios y a la Cruz de Yntter $\{30\}$ prettar Verdad en ella si asi lo hiçiere $\{31\}$ Dios le ayude Y sino selo demande $\{$ h. 230v $\}$ [margen superior: e] $\{1\}$ Y dijo Sujuro Yamen Y lo firmo Conmigo $\{2\}$ Siendo testigos Diego de Segouia y juan $\{3\}$ delo Rios por falta denotario Don $\{4\}$ Melchor de cotes Peraltta $=$ Matheo $\{5\}$ de segouia Diego de segouia $\mathrm{Ju}<\mathrm{an}>$ delos $\{6\}$ Rios

\{7\} [margen subrayado: Ynformaz<ion>] En el asientto de San Joseph de Aco $\{8\}$ bamba enveinttey dos dias del mes $\{9\}$ de febrero de mill y seisçientos Yo $\{10\}$ chentaY seis años el Doctor Don $\{11\}$ Melchor de cottes Peralta Cura Y $\{12\}$ Vicario de el venefiçio de conaica en $\{13\}$ laprouinçia de Angaraes para efecto $\{14\}$ delo contenido En la cauesa de Pro $\{15\}$ çeso hiçe parezer ante mi a vn $\mathrm{Yn}<$ dio $>\{16\}$ queporYnterpretaçion de Mateo $\{17\}$ de Segouia Ynterprete nombrado $\{18\}$ dijo 
llamarse thomas Luis y Ser $\{19\}$ natural del pueblo de vilcabamba $\{20\}$ del qual rreçeui juramento por $\{21\}$ Dios nuestro Señor y avna señal $\{22\}$ de cruz Y segun derecho Y so cargo $\{23\}$ del prometio desir verdad delo que $\{24\}$ Supiere y le fuese pregunttado $\{25\}$ Y siendolo Al tenor dela Cauessa $\{26\}$ deProsesso = dijo este testigo que $\{27\}$ lo que pasa es que abra tres dias que $\{28\}$ es alcalde de Vilca le embio a a $\{29\}$ visar Como $\mathrm{D}<\mathrm{on}>\mathrm{Ju}<\mathrm{an}>$ flores de Valdes $\{30\}$ tenientte general de esta proui<ncia $>\{31\}$ auia embiado Vino para Repartir \{h. 231\} [margen superior: e] $\{1\}$ Enlos pueblos y que fuese por quatro $\operatorname{Vo}\{2\}$ tijas que le tocauan y fue a $\mathrm{d}<\mathrm{ic}>$ ho pueblo $\mathrm{Y}\{3\}$ trajo tres Votijas en dos Odres y dejo vna $\{4\}$ en poder del alcalde para despues boluer $\{5\}$ porella y que el preçio de cada Votixa $\{6\}$ es adiez pesos y que $\mathrm{d}<\mathrm{ic}>$ ho Vino letiene en \{7\} vnacasa en este asiento para Repartirlo $\{8\}$ a los Yndios y que asi aquí Como enlos $\{9\}$ pueblos de estta prouincia Siempre an rre $\{10\}$ partido Vino los tenienttes por deçir es $\{11\}$ Uso y Costumbre y que quando emuia $\{12\}$ a cobrar la plata $\mathrm{de} d<\mathrm{ic}>$ ho vino en no dan $\{13\}$ dosela mette A los Yndios enlacarzel $\{14\}$ donde rreciuen muchas molestias y esto $\{15\}$ dijo Ser lauerdad So cargo del jura $\{16\}$ mentto fecho enque leydo y dado $\{17\}$ a entender por $\mathrm{d}<\mathrm{ic}>$ ha Ynterpretaz<ion $>\{18\}$ Seafirmo y rratifico y dijo ser de edad $\{19\}$ de quarenttay seis años poco mas o me $\{20\}$ nos no firmo porque dijo no sauer fir $\{21\}$ melo Yo Con $\mathrm{d}<\mathrm{ic}>$ ho Ynterprette $\mathrm{Y}$ testi\{22\} gos a faltta de Nottario Siendo testigos $\{23\}$ Diego de Segouia y Juan delos rrios $\{24\}$ presenttes = Doctor Don Melchor de cotes $\{25\}$ Peraltta $=$ Matheo de Segouia $=$ Diego $\{26\}$ de segouia $=$ Juan delos rrios

\{27\} [margen: $t<e s>t<$ igo $>\mid$ thomas quis $\mid$ Pe] Enel asientto de San Joseph de aCo $\{28\}$ bamba en Veintey dos dias del mes $\{29\}$ de febrero demill y seiscientos Yochenta $\{$ h. $231 \mathrm{v}\}$ [margen superior: e] $\{1\}$ Y seis años $=$ El Doctor Don Melchor $\{2\}$ decottes Peraltta Curay Vicario del ve $\{3\}$ nefiçio deconaica para la prosecuçion $\{4\}$ de estta causa hise parezer antemi a $\{5\}$ vnYndio que por $\mathrm{d}<\mathrm{ic}>$ ha Ynterpre $\{6\}$ taçion dijo llamarse thomas quispe $\{7\}$ Y ser natural del pueblo de Vilca $\{8\}$ bamba del qual rreceui juramento $\{9\}$ por Dios nuestro Señor y avna señal $\{10\}$ de cruz Segun forma de derecho $\{11\}$ Y auiendolo fecho prometio deçir $\{12\}$ Verdad de lo que le fuese preguntado $\{13\}$ Y siendolo Altenor dela cauesa de $\{14\}$ proseso $=$ dijo este testigo que fue al $\{15\}$ calde del Campo de estas punas el $\{16\}$ año pasado y por estta causa Resiuio $\{17\}$ envilcabamba siette botijas devino $\{18\}$ dequentta de el teniente general Don $\{19\}$ Juan flores de Valdes para Repartir $\{20\}$ A los Yndios de estos contornos y tra $\{21\}$ yendo $d<$ ic $>$ ho Vino Se le despeño enel $\{22\}$ Camino vna mulay seperdio el vino $\{23\}$ que tenia en los odres y lo pago a $d<i c>$ ho $\{24\}$ tenientte general de su plata porque $\{25\}$ no le castigase y ahora avisto En casa $\{26\}$ de thomas Luis dos odres llenos de $\{27\}$ Vino del $\mathrm{d}<\mathrm{ic}>$ ho teniente general que $\{28\}$ trajo de Vilcabamba paravender $\{29\}$ Y que lleba a diez pesos por cada botija \{h. 232\} [margen superior: e] $\{1\}$ Y esto dijo ser lauerdad So cargo de su $\{2\}$ Juramentto fecho en que leydo Ydado $\{3\}$ a enttender por $\mathrm{d}<\mathrm{ic}>$ ho ynterprete Sea $\{4\}$ firmo y rratifico y dijo ser de edad de $\{5\}$ quarentta años poco mas $\mathrm{O}$ menos $\mathrm{Y}$ lo firmo $\{6\}$ Conmigo y $\mathrm{d}<\mathrm{ic}>$ ho Ynterprette Siendo $\{7\}$ testigos Diego de segouia y Juan de $\{8\}$ los rrios por falta de Notario que 
$\{9\}$ Se hallaron presenttes $=$ Doctor Don $\{10\}$ Melchor de cotes Peralta $=$ thomas $\{11\}$ quispe $=$ Mateo de segouia $=$ Juan $\{12\}$ de los rrios Diego de Segouia

\{13\} [margen: $\mathrm{t}\langle\mathrm{es}\rangle \mathrm{t}\langle$ igo $>|$ Vicentte | Alonso] En el asientto de San Joseph de a $\{14\}$ Co[tachado: m]bamba en Veintey dos dias $\{15\}$ del mes de febrero demill y seisçientos $\{16\}$ Y ochentay seis años el doctor Don $\{17\}$ Melchor de cotes Peralta Curay $\{18\}$ Vicario dela Doctrina de conayca $\{19\}$ para la prosecuçion de esta causa hise $\{20\}$ pareçer ante mi avn Yndio quepor $\{21\}$ Ynterpretacion del Yntterprette $\{22\}$ Nombrado dijo llamarse Viçentte a\{23\}lonso y ser natural de el y Rejidor $\{24\}$ actualmente del qual rreceui ju\{25\}ramentto por Dios nuestro Señor $\{26\}$ y vna señal de Cruz Segun derecho $\{27\}$ Y so cargo del prometio desir verdad $\{28\}$ de lo que supiere y le fuesepregun $\{29\}$ tado y siendolo Al tenor del Auto $\{30\}$ que esta en la cauesa deproseso $=$ dijo $\{$ h. $232 \mathrm{v}\}$ [margen superior: e] $\{1\}$ Estte testigo que auistto Eneste asiento $\{2\}$ En casa de Tomas Luis Alcalde del $\{3\}$ Campo de las punas de este distritto $\{4\}$ dos Odres Conbino que trajo del pueblo $\{5\}$ de vilcabamba para vender alos $\{6\}$ Yndios dequentta del tenientte $\{7\}$ General Don $\mathrm{Ju}<\mathrm{an}>$ flores devaldes $\{8\}$ arraçon de diez pesos botija pero nosa $\{9\}$ be las que Entraron En los Odres, Y $\{10\}$ que esto esta envso y Costumbre $\mathrm{Y}\{11\}$ que asi $\mathrm{d}<\mathrm{ic}>$ ho tenientte Como los que a $\{12\}$ Conoçido an hecho lo mesmo y que es $\{13\}$ publico y laverdad So cargo de su $\{14\}$ Juramento fecho enque leydo Y $\{15\}$ dado aenttender por $\mathrm{d}<\mathrm{ic}>$ ha ynpterpre $\{16\}$ taçion se afirmo y rratifico y dijo $\{17\}$ Ser deedad de treinta años poco mas $\{18\}$ O menos no firmo porque dijo no sauer $\{19\}$ firmelo yo Con $d<i c>$ ho ynterprette $\{20\}$ Y testigos a falta de notario Sien $\{21\}$ dolos Juan delos rrios y Diego $\{22\}$ desegouia quese hallaron presentes $\{23\}$ Docttor Don Melchor de cotes Pe $\{24\}$ raltta = Matheo de segouia Juan $\{25\}$ de los rrios Diego de segouia

\{26\} [margen subrayado: Ju<an> cubia] En el asiento de San Joseph dea $\{27\}$ Cobamba en Veinte y dos dias $\{28\}$ del mes defebrero de mill y seis<cientos> $\{29\} \mathrm{Y}$ [subrayado: ochentta Y] seis años el Doctor $\{$ h. 233\} [margen superior: e] $\{1\}$ Don Melchor de cottes peraltta Curay $\{2\}$ Vicario del Veneficio de Conaica para la $\{3\}$ prosecuçion de estta causa hisepareser antemi $\{4\}$ avnYndio queporynterprettacion $\{5\}$ del yntterprette dijo llamarse $\mathrm{Ju}<\mathrm{an}>\{6\}$ Cubia y ser natural de este $\mathrm{d}<\mathrm{ic}>$ ho asiento \{7\} y en el Alcalde hordinario delos $\mathrm{Na}\{8\}$ turales del qual rreçeui Juramento $\{9\}$ por Dios nuestro Señor y auna Señal $\{10\}$ de cruz Segun derecho y Socargo del pro $\{11\}$ mettio deçir verdad delo que Supiere $\{12\}$ Y le fuesepreguntado y siendolo altenor $\{13\}$ de la cauesa deproseso dijo este testigo $\{14\}$ que Como tal Alcalde ha visto en $\{15\}$ Cassa de thomas Luis alcalde del campo $\{16\}$ dos Odres de vino el vno lleno y elotro $\{17\}$ hastta la mittad que lepareze abratres $\{18\}$ Votijas el qual a traydo $\mathrm{d}<\mathrm{ic}>$ ho thomas $\{19\}$ Luis del pueblo de vilcabamba Para $\{20\}$ Vender alos Yndios deeste asiento $\{21\}$ Y miches delas punas y quequatro $\{22\}$ botijas Son las que Siempre Serreparten $\{23\}$ y vna dejo el $d<i c>$ ho tomas en poder del $\{24\}$ Alcalde de vilcabamba disiendo $\{25\}$ yriapor ella y saue que $\mathrm{d}<\mathrm{ic}>$ ho Vino $\{26\}$ es de Don Ju<an> flores de Valdes $\{27\}$ tenienttegeneral de esta Prouincia $\{28\}$ delos Angaraes y queporcada $\{29\}$ Votija lepagan adiez pesos y que lo $\{30\}$ mismo an hecho los demas tenientes $\{$ h. $233 \mathrm{v}\}$ 
[margen superior: e] $\{1\}$ Sus Anteçesores y que es publico Y notorio $\{2\}$ y laverdad So cargo de su juramento $\{3\}$ fecho enque leydo y dado a enttender $\{4\}$ Por $\mathrm{d}<\mathrm{ic}>\mathrm{ha}$ Yntterpretaçion Seafirmo $\{5\}$ y rratifico y dijo serdeedad decinquenta $\{6\}$ años poco mas $\mathrm{O}$ menos no firmo porque $\{7\}$ dijo no sauer firmelo yo $C o n d<i c>$ ho Yn $\{8\}$ terprette y testigos a faltta de notario $\{9\}$ que lo fueron Diego de segouia y $\mathrm{Ju}<\mathrm{an}>\{10\}$ delos rrios que se hallaron presentes $=\{11\}$ Don Melchor de cotes Peralta $=\operatorname{Ma}\{12\}$ theo de Segouia $=$ Diego de Segouia $\{13\}$ Juan de los rrios

\{14\} [margen subrayado: Autto | Y depossito] En el asientto de San Joseph de $\{15\}$ Acobamba En tres dias del mes de $\{16\}$ março demill y seisçientos Yo $\{17\}$ chentta Yseis años $=$ el Docttor $\{18\}$ Don Melchor decotes peraltta $\{19\}$ Curay Vicario del venefiçio de $\{20\}$ Conaica Jurisdiçion delos Angaraes $\{21\}$ Digo que por quanto auiendo Ydo $\{22\}$ oy $\mathrm{d}<\mathrm{ic}>$ ho dia ala Igleçia de este asiento $\{23\}$ a dar la Comunion alos Yndios mis $\{24\}$ feligreses que tenia ya Confesados $\{25\}$ paraque Cumpliesen ConlaYgle $\{26\}$ çia por hauer Entrado y a la qua $\{27\}$ resma y por hauer hallado los $\{28\}$ mas deellos Embriagados dexe $\{29\}$ de darles la Comunion y abiendo lla $\{30\}$ mado a thomas Luis Yndio alcalde \{h. 234\} [margen superior: e] $\{1\}$ del Campo desttos Conttornos y pregunta $\{2\}$ dole Si los dos Odres de Vino que trajo $\{3\}$ de Vilcabamba los ttenia En ser Respondio \{4\} Aver bendido el vino del vno a los yndios $\{5\}$ que an benido aconfesarse porser asi Usso $\{6\}$ y Costumbre y le mande traer el odre $\{7\}$ de Vino que le auia quedado y del. y del $\{8\}$ que estaua baçio lopuse en depositto en $\{9\}$ Mattheo de Segouia para que lo tenga $\{10\}$ de Manifiesto y no acuda Conellos aper $\{11\}$ sona alguna hasttaque Otra cosa por mi $\{12\}$ Sele mande o porJuez Competente que $\{13\}$ de la causa Conosca pena de excomunion $\{14\}$ mayor y deque seprosedera Conttra el $\{15\}$ Como Combiniere por derecho y el dicho $\{16\}$ Mattheo de Segouia auiendolos rreceuido $\{17\}$ Se obligo a ttener en depositto $d<i c>$ ho Odre $\{18\}$ devino y el otro baçio y de no Enttre $\{19\}$ garlo hastta quepor mi Sele mande $\{20\}$ O por Juez Compettentte a lei de deposi $\{21\}$ tario R<eal> Comentariense. Y Solapena $\{22\}$ deella y paraque de ello Constte lo firmo $\{23\}$ Conmigo y Con los testigos Con quien $\{24\}$ actuo por faltta denotario quelo fueron $\{25\}$ Diego de Segouia y Juan delos Rios $\{26\}$ Presenttes $=$ Docttor Don Melchor $\{27\}$ de cottes Peraltta $=$ Mattheo de $\mathrm{Se}\{28\}$ gouia $=$ Diego de segouia $=\mathrm{Ju}<\mathrm{an}>$ delos Rios

\{29\} [margen subrayado: Autto | de rremiz<ion>] En el asientto de San Joseph de acobamba $\{30\}$ en Çinco dias del mes de Março demill Y \{h. 234v $\}$ [margen superior: e] $\{1\}$ seiscienttos Yochenttay seis años el Doctor $\{2\}$ Don Melchor de cottes Peraltta Curay- $\{3\}$ Vicario del Veneficio de Conaica visttos es $\{4\}$ ttos auttos y la culpa que deellos rresultta $\{5\}$ Conttra don $\mathrm{Ju}<a n>$ flores de Valdes teniente $\{6\}$ general destta prouincia delos angaraes $\{7\}$ hago rremiz[sobrescrito: s]ion de esta causa al ex<celentisimo>s<eñor> $\{8\}$ Duque dela Palatta Virrey de estos Rey<nos> $\{9\}$ para que Con su vistta proveay mande $\{10\}$ lo que fuere seruido y lo firme ante mi $\{11\}$ a faltta deNotario siendo testigos Juan $\{12\}$ delos rrios y Diego de segouia que se $\{13\}$ hallaron presenttes $=$ Docttor Don $\{14\}$ Melchor de cottes Peraltta $=$ Juan de $\{15\}$ los rrios y Diego de Segouia 
\{16\} [margen subrayado: Autto] En el pueblo de San Pedro de Moya \{17\} Jurisdiçion dela prouinçia delos an $\{18\}$ garaes en catorçe dias del mes demarço $\{19\}$ demill y seiscientos y ochentta y seis $\{20\}$ años $=$ El docttor Don Melchor decotes $\{21\}$ Peraltta Cura y Vicario de la Doctrina $\{22\}$ de Conaica = Digo que sin Embargo de $\{23\}$ hauer hecho autto de rremiçion en $\{24\}$ esta causa es presiso proseguir enella $\{25\}$ Por quentta evenido a este $\mathrm{d}<\mathrm{ic}>$ ho pueblo $\{26\}$ por ser del $\mathrm{d}<\mathrm{ic}>$ ho mi curato aconfesar los $\{27\}$ Yndios del por ttener notiçia que los $\mathrm{Yn}<$ dios $>\{28\}$ an traido vnos Odres llenos de vino $\{29\}$ para que se bendiese porquentta de $\{30\}$ Don $\mathrm{Ju}<\mathrm{an}>$ flores de Valdes teniente $\{31\}$ general dela $\mathrm{d}<\mathrm{ic}>$ ha Prouinçia y vsando $\{32\}$ dela facultad Suso citada dela proui<sion> $>$ h. 235 $\}$ [margen superior: e] $\{1\}$ de Veintte de febrero en el autto queba $\{2\}$ por cauesa mando quepor su tenor Se ex\{3\}Saminen los testigos que supieren delcaso $\{4\} \mathrm{Y}$ asi lo probey ante mi juridicamente $\{5\}$ a faltta de notario Siendo testigos $\{6\}$ Matheo de Leongarauitto $=\mathrm{y}$ Don $\{7\}$ Alejo Curiñaupa que se hallaron presen $\{8\}$ ttes $=$ Don Melchor de cotes de Peralta $\{9\}$ Mattheo de Leon garauitto $=\mathrm{D}<\mathrm{on}>$ Alexo $\{10\}$ Curiñaupa

\{11\} [margen subrayado: Nombra|miento] Enel pueblo de Moya en d $<$ ic $>$ ho dia Catorze $\{12\}$ demarço demill y seisçientos y ochenta $\{13\}$ Y seis años $=$ el docttor Don melchor $\{14\}$ de cottes Peraltta Curay Vicario del ve $\{15\}$ nefiçio de conaica jurisdiçion de Anga\{16\}raes, digo quepara la prosecuçion desta $\{17\}$ Causa es neçesario nombrarYnterprete $\{18\}$ Por serYndio los que an de declarar $\{19\}$ En ella por lo qual nombro aMatheo $\{20\}$ de Leon garauitto personaynteli $\{21\}$ jentte En la Lengua delos naturales $\{22\} \mathrm{Y}$ esttando presentte el suso $\mathrm{d}<\mathrm{ic}>$ ho aseto $\{23\} \mathrm{d}<\mathrm{ic}>$ ho nombramiento y juro a Dios $\{24\}$ y avna Cruz de vsar vieny fielmente $\{25\} \mathrm{d}<\mathrm{ic}>$ ho ofiçio si assi lo hiçiere Dios le ayude $\{26\}$ Y sino Selo demande y dijo si juro Y a $\{27\}$ men $^{1}$ Y lo firmo Conmigo y Conlos tes $\{28\}$ tigos que sehallaron presenttes a $\{29\}$ faltta de Nottario que lo fueron Don $\{30\}$ Alexo Curiñaupa y Pedro Poma $\{h .235 v\}$ [margen superior: e] $\{1\}$ Docttor Don Melchor decotes Peraltta $=\{2\}$ Mattheo de Leon garabitto $=\mathrm{D}<$ on $>$ Alexo $\{3\}$ Curiñaupa $=$ Pedro Poma

\{4\} [margen: D<on> Alexo | Curiñaupa] En el pueblo de San Pedro demoya $\{5\}$ Jurisdiçion dela Prouincia delos an $\{6\}$ garaes en quinçe dias del mes de março $\{7\}$ demill y seiscienttos y ochentay Seis años $\{8\}$ el Docttor Don Melchor de cotes Peralta $\{9\}$ Cura y vicario de la Doctrina deconaica $\{10\}$ Para la prosecuçion desta causa hizepa $\{11\}$ reçer anttemi avn yndio ladino en $\{12\}$ la Lengua Castellana y sin Embargo $\{13\}$ de serlo por $\mathrm{d}<\mathrm{ic}>$ ha ynterpretacion dijo $\{14\}$ llamarse Don Alejo Curiñaupa y ser $\{15\}$ prinçipal y curaca de este $\mathrm{d}<\mathrm{ic}>$ ho pueblo $\{16\}$ del qual rreçeui juramento por Dios $\{17\}$ nuestro Señor y vna Señal de cruz $\{18\}$ Segun derecho y So cargo del prome $\{19\}$ tio desir verdad de lo que supiere $\{20\}$ Y le fuesepreguntado y siendolo al $\{21\}$ tenor del autto que ba por cauesa $=$ dijo $\{22\}$ estte testigo que lo que saue es por auerlo $\{23\}$ Vistto queabra veinte dias poco mas $\{24\} \mathrm{O}$ menos que Emuio a abisar $\mathrm{D}<\mathrm{on}>\mathrm{Ju}<\mathrm{an}>\{25\}$ flores de Valdes teniente general $\{26\}$ deestaprouinçia fuesen por vino destte $\{27\}$ pueblo y fueXptoval rrafael y Do\{28\}mingo Estevan y trajeron dos

\footnotetext{
${ }^{1}$ Inclusión de estilo directo en el discurso.
} 
odres $\{29\}$ llenos de Vino En que dijeron auer $\{30\}$ quatro Votixas las quales Serrepar $\{31\}$ tieron a Lorenço Peña Alcalde or $\{$ h. 236$\}\{1\}$ dinario [margen superior: e] a Juan Marca Alcalde del $\{2\}$ Campo a Alonso y auri rrejidor y a Alonso \{3\} Chanca parauenderlas porquentta $\{4\}$ de $\mathrm{d}<\mathrm{ic}>$ ho tenientte arraçon de diez Pesos $\{5\}$ Cada Votija y que albaçiar $\mathrm{d}<\mathrm{ic}>$ ho Vino En $\{6\}$ las Votijas faltaba para llenarlas mas no $\{7\}$ poreso dejan de enterar porcadavna $\mathrm{d}<\mathrm{ic}>\mathrm{hos}\{8\}$ diez pesos y sabe que a abido Votija queno $\{9\}$ Sale mas que siette pesos y medio y que $\{10\}$ auiendo auido Una borrachera rriñe $\{11\}$ ron el Alcalde y rrejidor y ano auerlos $\{12\}$ apasiguado vbiera Suçedido vna des $\{13\}$ graçia Entre ellos y que las mulas $\{14\}$ E Yndios que ban a traer $d<i c>$ ho Vino $\{15\}$ Nunca seles paga el trauajo Siendo assi $\{16\}$ que ay destte pueblo al pueblo de acobamba $\{17\}$ a donde lo ban atraer diez y ocho leguas $\{18\}$ y queenViniendo a cobrar elYndio $\{19\}$ queno enttera los diez pesos decada $\{20\}$ Votija lo metten En la Carzel y no sale $\{21\}$ deella hastta auer hecho lapaga $Y\{22\}$ Saueque acada terçio que es de seis En $\{23\}$ Seis meses traen a estepueblo quatro $\{24\}$ Votijas de Vino dequenta de dicho $\{25\}$ tenientte y aunque este testigo juro $\{26\}$ En la rrecidençia que dio $\mathrm{d}<\mathrm{ic}>$ ho teniente $\{27\}$ abra dos años quenosebendia Vino $\{28\}$ porsu quentta lo hiso poruer que Otros $\{29\}$ hasian lo mesmo $\mathrm{Y}$ porque declararlo Selepodia Seguir algun perjuiçio porauer $\{$ h. 236v $\}$ [margen superior: e] $\{1\}$ Proseguido Con la bara demas deser al $\{2\}$ guaçil mayor perpetuo En lauilla deguan $\{3\}$ cauelica y que Entodos los pueblos deestta $\{4\}$ Prouincia Serrepartte bino dequenta de $\{5\} \mathrm{d}<\mathrm{ic}>$ ho tenientte En la conformidad dicha yes $\{6\}$ tto dijo Serlaverdad So cargo del juram<ento $>\{7\}$ fecho En que leydo $\mathrm{Y}$ dado a enttender $\{8\}$ por $\mathrm{d}<\mathrm{ic}>$ ha Ynterpretaçion Seafirmo $\mathrm{Y}\{9\}$ rratifico y dijo ser deedad dequarentay $\{10\}$ Seis años poco mas $O$ menos y lo firmo $\{11\}$ Conmigo y Con los testigos conquien actuo $\{12\}$ por faltta denotario que lo fueron Pedro $\{13\}$ Poma y Pedro chapa $=\mathrm{y} d<\mathrm{ic}>$ ho Yntter $\{14\}$ prette $=$ Doctor Don Melchor decotes $\{15\}$ Peraltta Don Alexo Curiñaupa $=\{16\}$ Matheo de Leon garauitto, Pedro poma $\{17\}$ Pedro Chapa

\{18\} [margen: Lorenço | Peña] En el pueblo de Moia dela prouinçia $\{19\}$ delos Angaraes en $\mathrm{d}<\mathrm{ic}>$ ho dia quinçe $\{20\}$ demarço demill y seiscientos Yo $\{21\}$ chenttaY seis años el Doctor Don $\{22\}$ MelchordeCottes Peraltta Curay vi $\{23\}$ cario dela Doctrina de Conaica para la $\{24\}$ prosecuçion de esta causa hise parezer $\{25\}$ Antte mi avnYndio que por $\mathrm{d}<\mathrm{ic}>$ ha Ynterpretaçion dijo llamarse Lo\{26\}renço Peña y ser alcalde hordinario $\{27\}$ de este $d<i c>$ ho pueblo del qual rreçeui $\{28\}$ juramentto por Dios nuestro Señor \{h. 237\} [margen superior: e] $\{1\}$ Yauna Señal de cruz Segun derecho $\{2\}$ y So cargo del prometio decir verdad $\{3\}$ de lo que supiere y le fuesepreguntado $\{4\}$ y siendolo al tenor delacauesa depro $\{5\}$ çeso $=$ dijo este testigo que saue que Xp[tova]l \{6\} Rafael y Domingo Esteuan fueron $\{7\}$ al pueblo de acobamba abraveintte $\{8\}$ dias a traer vino dequenta del the $\{9\}$ nienttegeneral Don $\mathrm{Ju}<\mathrm{an}>$ flores de $\{10\}$ Valdes y que trajeron dos odres llenos $\{11\}$ de vino para uenderlos por su quenta $\{12\}$ arraçon de diez pesos Cada votija y q<ue $>\{13\}$ a este testigo Como tal Alcalde le toca $\{14\}$ vna y las demas Se rreparttieron $\{15\}$ a Juan marca alcalde del campo $\{16\}$ aAlonso y auri Rejidor y a Alonsso $\{17\}$ chanca y que de cada Votija no Sale $\{18\}$ mas que siette pesos y medio y cada $\{19\}$ año serrepartten por quenta de 
$\mathrm{d}<\mathrm{ic}>$ ho $\{20\}$ tenientte En estepueblo ocho Votijas $\{21\}$ de Vino y en estta Conformidad $\{22\}$ En los demas pueblos destta Juris<diccion> $>23\}$ Y queno seles paga Su trauajo alos $\{24\}$ Yndios queuan por $d<$ ic $>$ ho Vino ni me $\{25\}$ nos las mulas que lo traen y quando $\{26\}$ Vienen a la cobrança al queno da los $\{27\}$ diez pesos Cometen En la carzel y no sale $\{28\}$ deella hasta quepague y esto dijo ser $\{29\}$ lauerdad So cargo de su juramentto $\{30\}$ fecho En que leido $\mathrm{Y}$ dado aentender $\{\mathrm{h} .237 \mathrm{v}\}$ [margen superior: e] $\{1\}$ Seafirmo y rratifico y dijo ser deedad $\{2\}$ de cinquentta años poco mas $\mathrm{O}$ menos $\{3\}$ No firmo porque dijo no sauer firme $\{4\}$ lo yo Con $\mathrm{d}<\mathrm{ic}>\mathrm{ho}$ Ynterprette y testigos a $\{5\}$ faltta denotario que lo fueron Pedro $\{6\}$ Poma y Pedro Chapa que se hallaron $\{7\}$ presenttes $=$ Docttor Don Melchor $\{8\}$ de cottes Peraltta Mattheo de Leon \{9\} Garauitto, Pedro Poma Pedro Chapa

$\{10\}$ [margen subrayado: $\mathrm{t}<\mathrm{es}>\mathrm{t}<\mathrm{igo}>\mid \mathrm{Ju}<\mathrm{an}>$ marca] En el pueblo de San Pedro demoya de $\{11\}$ laprouinçia delos Angaraes en $\mathrm{d}<\mathrm{ic}>$ ho $\{12\}$ dia quinçe deMarço de mil y seis<cientos> y ochenttay seis años, el Doctor Don $\{13\}$ Melchor de Cotes Peralta Curay vi $\{14\}$ cario del venefiçio de Conaica para $\{15\}$ la prosecucion destta Causa hizepareçer $\{16\}$ antte mi avn Yndio quepor $\mathrm{d}<\mathrm{ic}>\mathrm{haYn}\{17\}$ terpretaçion dijo llamarse Juan marca $\{18\}$ y ser Alcalde del campo del qual rre $\{19\}$ ceui juramentto por Dios nuesttro $\{20\}$ Señor y auna Señal decruz Segun $\{21\}$ derecho y socargo del prometio deçir $\{22\}$ delo que supiere y le fuesepreguntado $\{23\}$ Y siendolo Altenor dela cauesa de $\{24\}$ proçeso que le fue leyda $=$ dijo este tes $\{25\}$ tigo que saue Por auerlo visto que a $\{26\}$ bra Veinte dias que fueren porel $\{27\}$ rrafael y Domingo Estevan alpue<blo> $\{28\}$ de acobamba a traer El vino que sse $\{29\}$ rrepartte enesepueblo porquentta $\{\mathrm{h}$. $238\}$ [margen superior: e] $\{1\}$ de Don Juan flores de Valdes teni $\{2\}$ entte general destta prouinçia y auiendo $\{3\}$ llegado trajeron dos odres llenos y a $\{4\}$ estte testigo le dieron Una Votija para $\{5\}$ quelasvendiese y las demas a Lorenço $\{6\}$ Peña alcalde hordinario destepueblo \{7\} a Alonso y auri rrejidor y a Alonso chanca $\{8\}$ haçiendoles Cargo porcadaVottija $\{9\}$ adiez pesos y por esttar algo baçia labotija $\{10\}$ Y ser pequeña No saco este testigo mas $\{11\}$ de siette pesos y medio mas no por eso $\{12\}$ dejara depagar $\mathrm{d}<\mathrm{ic}>$ hos diez pesos porque $\{13\}$ leapremiaran aello y aora dias en $\{14\}$ tre el Alcalde hordinario y rrejidor $\{15\}$ Ubo pendençia porauerse embriagado $\{16\}$ Con $\mathrm{d}<\mathrm{ic}>$ ho vino y ano auerlos mettido $\{17\}$ en pas Ubiera Suçedido alguna des $\{18\}$ graçia y que alos Yndios que ban $\{19\}$ a traer $\mathrm{d}<\mathrm{ic}>$ ho Vino Ni las Mulas $\{20\}$ que lo cargan Se les paga auiendo $\{21\}$ mas deveintte leguas y que cada año \{22\} Serrepartten enestepueblo ocho $\{23\}$ Votijas de Vino quatro cada Seis $\{24\}$ meses y la mesma Cantidad en $\{25\}$ Cadapueblo desta jurisdiçion y en $\{26\}$ Cumpliendose el termino los meten $\{27\}$ en la carzel y no salen de ella hasta $\{28\}$ auerpagado lo qual han hecho todos $\{\mathrm{h} .238 \mathrm{v}\}$ [margen superior: e] $\{1\}$ los thenienttes y estto dijo Ser verdad $\{2\}$ So cargo de su juramento fecho en $\{3\}$ que leydo seafirmo y rratifico $Y\{4\}$ dijo Seer deedad demas dequarenta $\{5\}$ años no firmo porq $\langle$ ue $>$ dijo no sauer fir $\{6\}$ melo yo Con $d<i c>h o$ ynterprette siendo $\{7\}$ testigos Pedro Poma y Pedro chapa $\{8\}$ Docttor Don Melchor decotes Peralta $\{9\}$ Pedro Poma $=$ Matheo de Leon $\{10\}$ garauitto $=$ Pedro chapa 
$\{11\}$ [margen subrayada: ttes <timonio $>\mid \mathrm{Xp}<$ toval $>$ rrafael] En el pueblo de San Pedro demoya $\{12\}$ Jurisdiçion delaprouinçia de $A n\{13\}$ garaes en $\mathrm{d}<\mathrm{ic}>$ ho dia quinçe demarço $\{14\}$ demill y seiscientos y ochentay seis $\{15\}$ años $=$ el Docttor Don Melchor decotes $\{16\}$ Peraltta Curay Vicario del venefi $\{17\}$ çio de conaica para la procecusion de $\{18\}$ esta causa hiceparezer antte mi avn $\{19\}$ Yndio quepor $\mathrm{d}<\mathrm{ic}>$ haYnterpretaz<ion> $\{20\}$ dijo llamarse Xptoval rrafael $\{21\}$ y ser natural destepueblo delqual $\{22\}$ rreceui juramentto por Dios nuestro $\{23\}$ Señor y avna señal de cruz Segun de $\{24\}$ recho y So cargo del prometio desir $\{25\}$ verdad delo que supiere y le fuese $\{26\}$ preguntado y siendolo al tenor de $\{27\}$ la cauesa deproçeso que le fue leyda $\{28\}$ Dijo estte testigo que abra mas de $\{29\}$ Veintte dias que fue alpueblo de $\{30\}$ acobamba en Compañia de Domi<ngo> $\{$ h. 239\} [margen superior: e] $\{1\}$ Estevan a traer dos odres llenos devino $\{2\}$ que le entrego el teniente general $\{3\}$ de estaprouinçia Don Ju<an> flores $\{4\}$ deValdes para que los entregasse $\{5\}$ enesttepueblo alos mandones y se $\{6\}$ bendiesen porsu quenta y auiendolos $\{7\}$ traido y entregado serrepartio vna $\{8\}$ Votija $\mathrm{Al}$ alcalde Ordinario y las $\{9\}$ demas al alcalde del campo al $\operatorname{Re}\{10\}$ jidor y a Alonso Chanca y sauepagar $\{11\}$ por cada Votija adiez pesos y cada $\{12\}$ año Serrepartten Ocho y queno se le $\{13\}$ pago Su trauajo ni el de las mulas $\{14\}$ que lleuo pordeçir estta encostum $\langle$ bre $>\{15\}$ auiendo Veinte leguas de camino $\{16\}$ y que en los demas pueblos Se hace $\{17\}$ la mesma rreparticion y quando Vienen $\{18\}$ a la cobrança elyndio queno da $\{19\}$ laplatta lo ponen en la carzel y no sale de $\{20\} 11$ a Sin que ayapasado y esto dijo ser $\{21\}$ laverdad So cargo de su juramentto $\{22\}$ fecho en que leydo Seafirmo y rratifico $\{23\}$ y dijo ser deedad dequarentay ocho $\{24\}$ años poco mas $O$ menos No firmo porque $\{25\}$ dijo no sauer firmelo io. Con $\mathrm{d}<\mathrm{ic}>$ ho ynter $\{26\}$ prette y testigos a faltta de Notario $\{27\}$ que lo fueron Pedro Chapa y Pedro $\{28\}$ Poma presenttes = Docttor Don $\operatorname{Mel}\{29\}$ chor decottes Peraltta $=$ Matheo de $\{30\}$ leon Garauitto $=$ Pedro Poma $=\mathrm{P}<$ edro $>$ chapa

\{h. 239v $\}$ [margen superior: e] $\{1\}$ [margen subrayado: Autto] En el pueblo de San Pedro de Moya $\{2\}$ Jurisdiçion dela prouincia delos anga $\{3\}$ raes en quinçe dias del mes demarço $\{4\}$ demill y seiscienttos y ochenttay seis $\{5\}$ años, el Docttor Don Melchor de cottes $\{6\}$ Peraltta Curay Vicario del Venefiçio $\{7\}$ de Conaica hago rremision desttos $\{8\}$ auttos al ex<celentisimo> Señor Duque de la $\{9\}$ Palatta Virrey de estos rreynos para $\{10\}$ que Con vistta deellos mande lo que fuere $\{11\}$ Seruido y lo firme antte mi Juridica $\{12\}$ mentte a faltta de Notario Siendo $\{13\}$ testigos Mattheo de Leon garabitto $\{14\}$ y DonAlexo Curiñaupa que se $\{15\}$ hallaron presenttes $=$ Docttor Don $\{16\}$ Melchor de cottes Peraltta $=$ Matheo $\{17\}$ deleon garabitto $=$ Don Alexo Curi $\{18\}$ ñaupa

\{19\} Concuerda estte traslado Con los auttos Ori $\{20\}$ ginales de donde se saco quequedan $\{21\}$ en mi poder Con los quales Secorrijieron $\{22\}$ y ban Çierttos y Verdaderos aqueme $\{23\}$ Refiero y para que deello Conste donde $\{24\}$ combenga lo firme ante mi juridica $\{25\}$ mentte afaltta denotario Siendo $\{26\}$ testigos a lasaca Matheo de Leon $\{27\}$ garauitto y Pedro Poma fecho $\{28\}$ En el pueblo deMoia en veintey seis $\{29\}$ dias del mes de março demill y seis<cientos $>\{30\}$ Y ochenttaY seis años $=$ 
Doctor Don $\{$ h. 240 [margen superior: e] $\{1\}$ Melchor de cottes Peraltta $=$ Mattheo $\{2\}$ de Leon garauitto $=$ Pedro Poma

\{3\} [margen subrayado: Cauessa | deProceso] En el asientto de San Joseph dea $\{4\}$ cobamba dela Jurisdicion delaproui<ncia $>\{5\}$ delos Angaraes en Veintte y vn dias del mes de febrero demill y seisçientos $\{6\}$ y ochenttay seis años $=$ el Docttor Don \{7\} Melchor de cottes Peraltta Cura y Vi $\{8\}$ cario dela Doctrina de Conaica $=$ Digo $\{9\}$ que Por quantto evenido aeste dicho $\{10\}$ asientto porser anexo al $\mathrm{d}<\mathrm{ic}>$ ho mi curato $\{11\}$ a confesar los Yndios que ay en el por $\{12\}$ esttar tan proxima la quaresma a $\{13\}$ donde tube notiçia auia embiado Don $\{14\} \mathrm{Ju}<\mathrm{an}>$ flores de Valdes tenientegeneral $\{15\}$ deestta $d<i c>$ ha prouinçia dos odres llenos $\{16\}$ de vino para que se bendiesen por suq<uenta> $\{17\}$ por mano de thomas Luis yndio Al $\{18\}$ calde del campo deque en Otras Oca $\{19\}$ ciones que lo an traido an rresultado $\{20\}$ entre los Yndios pendençias y salido $\{21\}$ algunos heridos y aorapodian suseder $\{22\}$ muchos disgustos por ser $\mathrm{d}<\mathrm{ic}>$ ho Vino $\{23\}$ traido en odres Contrabiniendo alas $\{24\}$ Ordenanças y prouiçiones del Real $\{25\}$ gouierno y para Obiar estos escanda $\{26\}$ los taquies y borracheras Como ttal $\{27\}$ Curay vicario Valiendome dela fa $\{28\}$ culttad que seme Conçede por la pro $\{29\}$ uiçion despachada por el excelen $\{\mathrm{h} .240 \mathrm{v}\}\{1\}$ tisimo [margen superior: e] Señor Duque dela Palata Virrey $\{2\}$ de estos Reynos su fecha de Veintte de $\{3\}$ febrero del año pasado de seis<cientos> Yo $\{4\}$ chenttay quatro para que los Curas $\{5\}$ puedan actuar Contra los Juezes Or $\{6\}$ dinarios hize estacauesa deprozeso para \{7\} que Por su thenor Se exsaminen $\{8\}$ los testigos que supieren delcaso porcom $\{9\}$ Venir asi al seruicio deambas $\mathrm{Ma}\{10\}$ gesttades y porque sus Yndios los que $\{11\}$ ande declarar senombrarayntter $\{12\}$ prette para ello y asi lo probey an $\{13\}$ tte mi Juridicamentte a faltta de $\{14\}$ Notario Siendo testigos Juan de $\{15\}$ Los rrios y Diego de segouia que lo $\{16\}$ firmaron Conmigo $=$ Docttor Don $\{17\}$ Melchor de cotes Peralta $=$ Diego $\{18\}$ de Segouia $=$ Juan delos rrios $=$

\{19\} [margen subrayado: Nombra|miento | deYnter|prette] En el asientto de San Joseph de aco $\{20\}$ bamba en dicho dia veintey vno de $\{21\}$ febrero demill y seiscientos Yo\{22\}chenttay seis años el Docttor Don $\{23\}$ Melchor de cottes Peralta CuraY $\{24\}$ Vicario del Venefiçio de conaica en $\{25\}$ laprouincia de Angaraes = Digo $\{26\}$ que para proseguir enesta causa $\{27\}$ es necesario Nombrar Ynter $\{28\}$ prette porser Yndios los quean $\{29\}$ de declarar enella y para ello $\{30\}$ nombre a Matheo de Segouia $\{\mathrm{h}$. 241\} [margen superior: e] $\{1\}$ Persona yntelijentte en la Lengua delos $\{2\}$ Naturales y esttando presente el suso $\mathrm{d}<\mathrm{ic}>$ ho $\{3\}$ açetto $\mathrm{d}<\mathrm{ic}>$ ho nombramientto y juro a Dios $\{4\}$ y ala cruz deYnterprettar Verdad en $\{5\}$ ella si asi lo hiçiere Dios leayude y Sino $\{6\}$ Selo demande y dijo Sijuro y amen Y lo $\{7\}$ firmo Conmigo Siendo testigos Diego $\{8\}$ de Segouia y Juan de los rrios por falta $\{9\}$ deNotario $=$ Don Melchor decotes $\operatorname{Pe}\{10\}$ raltta $=$ Mattheo de Segouia $=$ Diego de $\{11\}$ Segouia $J u<a n>$ de los rrios

\{12\} [margen: Ynfor|macion] En el asientto de San Joseph de acobamba $\{13\}$ enveinttey dos dias del mes de febrero $\{14\}$ demill y seiscientos y ochenta y seis $a<\tilde{n o s}>\{15\}$ el Docttor Don Melchor decotes Peralta $\{16\}$ Curay Vicario del venefiçio deconayca $\{17\}$ en laprouinçia de Angaraes para $\{18\}$ efectto delo Contenido en la 
cauesa de $\{19\}$ proçeso hiseparezer antte mi avn Yndio $\{20\}$ queporynterpretaçion de Mateo $\{21\}$ desegouia ynterprette Nombrado $\{22\}$ dijo llamarse thomas Luis y serna $\{23\}$ tural del pueblo de Vilcabamba $\{24\}$ del qual rreçeui juramento por Dios $\{25\}$ nuestro señor y auna señal de Cruz $\{26\}$ Segun derecho y so cargo del prometio $\{27\}$ deçir Verdad delo que supiere y lefuese $\{28\}$ Preguntado y siendolo al ttenor dela $\{29\}$ Cauesa deproçeso $=$ Dijo este ttesttigo $\{\mathrm{h} .241 \mathrm{v}\}$ [margen superior: e] $\{1\}$ que lo quepasaes que abra tres dias que $\{2\}$ el alcalde deVilca[tachado:**] embio aavuisar Como $\{3\}$ Don $\mathrm{Ju}<\mathrm{an}>$ flores de Valdes tenientegen<eral $>\{4\}$ deestaproui<ncia> auia embiado Vino para $\{5\}$ rrepartir en los pueblos y que fuesepor $\{6\}$ quatro Votijas que le tocauan y fuead<icho> $\{7\}$ pueblo y trajo tres Votijas en dos odres $\{8\}$ y dejo vna en poder del alcalde para $\{9\}$ despues voluer porella y que elpreçio $\{10\}$ de cada Votija es adiez pesos y que $\mathrm{d}<\mathrm{ic}>$ ho $\{11\}$ Vino le tiene en vna casa eneste asiento $\{12\}$ para rrepartirlo alos Yndios Y que $\{13\}$ asi aqui Como enlos pueblos de esta $\{14\}$ Prouinçia Siempre an rreparttido $\{15\}$ Vino los tenienttes por deçir es uso $\{16\}$ y Costumbre y que quando emuia $\{17\}$ a Cobrar la platta de $d<i c>$ ho Vino en $\{18\}$ No dandosela mette a los Yndios en la $\{19\}$ Carzel donderreciuen muchas moles $\{20\}$ tias y estto dijo ser lauerdad Socargo $\{21\}$ de su juramento $\mathrm{f}\langle\mathrm{ec}>$ ho enque leydo $\{22\}$ y dado aentender por $\mathrm{d}<\mathrm{ic}>$ haYnter $\{23\}$ prettaçion Seafirmo y rratifico $\{24\}$ y dijo ser deedad dequarentaY Seis $\{25\}$ años poco mas $O$ menos no firmo por $\{26\}$ que dijo no sauer firmelo yo Con $\mathrm{d}<\mathrm{ic}>$ ho $\{27\}$ ynterprette $\mathrm{y}$ testigos a falta deno\{28\}tario Siendo testigos Diego desegouia $\{29\}$ y $\mathrm{Ju}<\mathrm{an}>$ delos rrios presentes $=$ Doctor Don $\{30\}$ Melchor decotes Peralta $=$ Mattheo $\{$ h. 242 $\}$ [margen superior: e] $\{1\}$ desegouia $=$ Diego de segouia $=$ $\mathrm{Ju}<\mathrm{an}>\operatorname{delos}\{2\}$ rrios

\{3\} [margen subrayado: $\mathrm{t}<\mathrm{es}>\mathrm{t}<\mathrm{igo}>\mid$ thomas $\mid$ quispe] En el asientto de San Joseph de aco $\{4\}$ bamba en veinttey dos dias del mes de $\{5\}$ febrero demill y seisçientos Yochenta $\{6\}$ y seis años $=$ el Docttor $\mathrm{D}<\mathrm{on}>$ Melchor decotes $\{7\}$ Peraltta Curay Vicario del Venefiçio $\{8\}$ deconayca para laproçecuçion de estacausa $\{9\}$ hizepareser anttemi avn Yndio que $\{10\}$ por $\mathrm{d}<\mathrm{ic}>$ haYnterpretaçion dijo llamarse $\{11\}$ thomas quispe y ser natural del pueblo $\{12\}$ de Vilcabamba del qual rreçeui jura $\{13\}$ mentto por Dios nuestro Señor y avna $\{14\}$ Señal de cruz Segun forma de derecho $\{15\}$ y auiendolo fecho prometio desir ver $<$ dad $>\{16\}$ de lo que sele fuese preguntado y $\operatorname{sien}\{17\}$ dolo $\mathrm{Al}$ tenor delacauesa deproz[sobrescrito: $\mathrm{s}] \mathrm{eso}=$

\{18\} dijo esttestigo que fue alcalde del campo \{19\} de estas punas el año pasado y poresta causa $\{20\}$ Reçiuio en Vilcabamba Siete Votijas $\{21\}$ deVino dequentta del tenientegen<eral> $\{22\}$ Don Ju<an> flores de Valdes para rrepar $\{23\}$ tir alos Yndios de estos Contornos Y $\{24\}$ trayendo $d<i c>$ ho Vino Sele desPeño en $\{25\}$ el Camino Una mula y seperdio el $\{26\}$ Vino que venia enlos odres $Y$ lo pago $\{27\}$ al $d<$ ic $>$ ho tenienttegeneral de suplata $\{28\}$ Porqueno le castigase $Y$ ahora A visto $\{29\}$ encasa de thomas Luis dos odres llenos $\{30\}$ de Vino del $d<i c>$ ho teniente que trajo de $\{h .242 v\}$ [margen superior: e] $\{1\}$ Vilcabamba parauender y que lleua $\{2\}$ a diez pesos porcada Votija y estto dijo $\{3\}$ Ser lauerdad So cargo del juram<ento> $\{4\}$ fecho en que leyda y dado a entender $\{5\}$ por $\mathrm{d}<\mathrm{ic}>$ ho ynterprette Seafirmo y rra $\{6\}$ tifico y dijo ser deedad 
dequarenta $\{7\}$ años poco mas $\mathrm{O}$ menos y lo firmo Con $\{8\}$ migo y $\mathrm{d}<\mathrm{ic}>$ ho ynterprette Siendo $\{9\}$ testigos Diego de segouia y Juan $\{10\}$ de los rrios por faltta denotario $\{11\}$ que Se hallaron presentes $=$ Doctor $\{12\}$ Don Melchor de cotes Peraltta $=\mathrm{Ma}\{13\}$ theo de Segouia $=$ thomas quispe $=\{14\} \mathrm{Ju}<\mathrm{an}>$ delos rrios diego de Segouia

$\{15\}$ [margen subrayado: $\mathrm{t}<\mathrm{es}>\mathrm{t}<$ igo $>$ Vicente $\mid$ Alonso] En el asientto de San Joseph de aco $\{16\}$ bamba enveinttey dos dias del mes de $\{17\}$ febrero de mill y seisçientos y ochenta $\{18\}$ y seis años el Docttor Don Melchor $\{19\}$ de Cotes Peraltta Curay Vicario $\{20\}$ dela Doctrina de conayca para lapro\{21\}Secuçion deestacausa hize parezeran $\{22\}$ ttemi avnyndio queporynterpre $\{23\}$ taçion del ynterprette Nombrado $\{24\}$ dijo llamarse Vicentte Alonso y Ser $\{25\}$ natural deel y rrejidor actual $\{26\}$ mentte del qual rreçeui Juramento $\{27\}$ por Dios nuestro Señor y avna señal $\{28\}$ decruz Segunderecho y so cargo del $\{29\}$ Prometio desir Verdad de lo quesupiere $\{$ h. 243\} [margen superior: e] $\{1\}$ Y le fuese preguntado y siendolo al $\{2\}$ tenor del autto queestta enlacauesa $\{3\}$ deproseso $=$ dijo este testigo que auisto $\{4\}$ enestte asientto encasa de thomas luis $\{5\}$ Alcalde del Campo delas punas deeste $\{6\}$ distritto dos odres Con vino que traxo $\{7\}$ del pueblo de Vilcabamba paraven $\{8\}$ der alos Yndios dequentta del tte $\{9\}$ nienttegeneral Don $\mathrm{Ju}<\mathrm{an}>$ flores $\{10\}$ de Valdes arraçon de diezpesos botija $\{11\}$ Pero no saue las que entraron enlos $\{12\}$ Odres y que esto estta envso y costumbre $\{13\}$ y que asi $\mathrm{d}<\mathrm{ic}>$ ho tenientte Como los que $\{14\}$ a conoçido han hecho lo mesmo y que es $\{15\}$ publico y lauerdad Socargo desuju $\{16\}$ ramentto fecho en que Leydo $\{17\}$ y dado aenttender por dicha $\operatorname{Yn}\{18\}$ terprettaçion Seafirmo y Ratifico $\{19\}$ y dijo ser de edad detreinta años $\{20\}$ poco mas $O$ menos no firmo porquedijo $\{21\}$ No sauer firmelo yo Con $\mathrm{d}<\mathrm{ic}>$ ho yntter $\{22\}$ prette y testigos afaltta denotario $\{23\}$ Siendolos $\mathrm{Ju}<\mathrm{an}>$ delos rrios y Diego $\{24\}$ desegouia que Se hallaron presentes $\{25\}$ Doctor $D<$ on> Melchor de cotes Peralta $\{26\}$ Matheo de Segouia = Juan de $\{27\}$ los rios Diego de Segouia

$\{28\}$ [margen: $\mathrm{t}<\mathrm{es}>\mathrm{t}<\mathrm{igo}>\mid \mathrm{Ju}<\mathrm{an}>$ cubia] Enel asientto de San Joseph dea $\{\mathrm{h} .243 \mathrm{v}\}$ $\{1\}$ cobamba [margen superior: e] en Veintey dos dias del mes de $\{2\}$ febrero demill y seis<cientos> y ochenta y seis años \{3\} El Docttor Don Melchor decotes Pe $\{4\}$ raltta Curay Vicario del veneficio de Co $\{5\}$ nayca para laprosecucion de esta Causa $\{6\}$ hise parezer anttemi avnYndio quepor $\{7\}$ ynterpretaçion del $d<i c>$ ho ynterprette dijo $\{8\}$ llamarse $\mathrm{Ju}<\mathrm{an}>$ Cubiay ser natural de este $\{9\} \mathrm{d}<\mathrm{ic}>$ ho asientto y en el alcalde hordinario $\{10\}$ de los naturales del qual rreceui jura $\{11\}$ mentto por Dios nuestro $\mathrm{s}<$ eñor> y auna Señal $\{12\}$ de Cruz Segun derecho y so cargo del pro $\{13\}$ mettio desir verdad de lo que supiere $\{14\}$ y le fuese preguntado y siendolo alte $\{15\}$ nor de la cauesa deproçeso dijo este testigo $\{16\}$ que como tal alcalde auistto en casa deto $\{17\}$ mas Luis alcalde del campo dos odres de $\{18\}$ Vino el vno lleno y elotro asta la mitad $\{19\}$ que lepareze abra tres Votijas el qual a $\{20\}$ traydo $d<i c>$ ho thomas Luis del pueblo de $\{21\}$ Vilcabamba parauender a los Yndios $\{22\}$ deeste asientto y miches delas punas $\{23\} \mathrm{y}$ que quatro Votijas Son las que siempre $\{24\}$ Serrepartten y vna dejo el $\mathrm{d}<\mathrm{ic}>$ ho thomas $\{25\}$ Luis enpoder del alcalde de Vilcabam $\{26\}$ ba disiendo yria porella y saue que $\mathrm{d}<\mathrm{ic}>$ ho $\{27\}$ Vino es de Don $\mathrm{Ju}<\mathrm{an}>$ flores de Valdes $\{28\}$ thenientte general 
deestaprouinçia de $\{29\}$ los Angaraes y que porcada Votija le $\{30\}$ pagan adiez pesos $Y$ que lo mesmo han hecho $\{31\}$ los demas tenienttes sus antesesores y que es publico $\mathrm{Y}$ notorio Y lauerdad So cargo de su \{h. 244\} [margen superior: e] $\{1\}$ Juramentto fecho enque leydo y dado $\{2\}$ aenttender por $\mathrm{d}<\mathrm{ic}>$ hayntterpretaçion $\{3\}$ Seafirmo y rratifico y dijo ser deedad $\{4\}$ de cinquentta años poco mas $O$ menos No $\{5\}$ firmo porque dijo no sauer firmelo $\{6\}$ yo Con $\mathrm{d}<\mathrm{ic}>$ ho Ynterprette y testigos afalta $\{7\}$ denottario que lo fueron Diego Segouia $\{8\}$ y Ju<an> delos Rios que se hallaronpre $\{9\}$ Senttes = Docttor Don Melchor decottes $\{10\}$ Peraltta $=$ Mattheo de Segouia $=$ Diego $\{11\}$ desegouia $=$ $\mathrm{Ju}<\mathrm{an}>$ delos rrios

\{12\} [margen subrayado: Auto | Y deposito] En el asientto de San Joseph de acobam $\{13\}$ ba en tres dias del mes de Março demill $\{14\}$ y seiscienttos y ochentta y Seis años = El $\{15\}$ Docttor Don Melchor de cotes Peralta $\{16\}$ Cura y Vicario del Venefiçio deconaica $\{17\}$ Jurisdiçion delos Angaraes = digo que $\{18\}$ porquantto auiendo ydo oy $\mathrm{d}<\mathrm{ic}>$ ho dia $\{19\}$ ala Ygleçia deeste asiento a darla Co $\{20\}$ munion alos Yndios mis feligreses que $\{21\}$ tenia ya Confesados para que Cumplie $\{22\}$ sen Con la Ygleçiapor auer entrado $\{23\}$ ya la quaresma y por hauer hallado $\{24\}$ los mas deellos embriagados deje dedar\{25\}les lacomunion y auiendo llamado $\{26\}$ a thomas Luis Alcalde delcampo de $\{27\}$ estos Contornos y preguntadolesi los dos $\{28\}$ odres de Vino que trajo de Vilcabamba \{29\} los tenia en ser rrespondio auer Vendido \{30\} elvino del vno alos Yndios q<ue> an venido $\{\mathrm{h} .244 \mathrm{v}\}$ [margen superior: e] $\{1\}$ A confesarse por ser asi vso y Costumbre $\{2\}$ y le mande traer el odre de Vino que $\{3\}$ leauia quedado y del, y del que estaua $\{4\}$ baçio lo puse endepositto en Matheo $\{5\}$ desegouia paraque lo tenga demani $\{6\}$ fiestto y no acuda Conellos apersona $\{7\}$ Alguna hasttaque Otra cosa por mi $\{8\}$ Se le mande $O$ por Juez Competente $\{9\}$ que delacausa Conosca pena de exco $\{10\}$ munion mayor y deque seproçedera $\{11\}$ Contrael como Combiniere porderecho $\{12\}$ y el $\mathrm{d}<\mathrm{ic}>$ ho Matteo desegouia auien $\{13\}$ dolos rreceuido Seobligo atteneren $\{14\}$ depositto $\mathrm{d}<\mathrm{ic}>$ ho Odre lleno devino y el $\{15\}$ Otro baçio ydeno entregarlo hasta $\{16\}$ quepor mi sele mande $O$ porotro juez $\{17\}$ Compettentte aley dedepositario $\mathrm{R}<$ eal $>\{18\}$ Comentariense y so la pena deella $\{19\}$ y para $\mathrm{q}<\mathrm{ue}>$ deello Constte lo firmo Con $\{20\}$ migo y Con los testigos Conquien actuo $\{21\}$ por faltta denotario que lo fueron $\{22\}$ Diego desegouia y Juan delos rrios $\{23\}$ presenttes = Docttor Don Melchor de $\{24\}$ Cottes Peraltta = Mattheo de segouia $\{25\}$ Diego desegouia $=$ Juan delos rrios

\{26\} [margen subrayado: autto | de rremiss<ion>] En el asientto de San Joseph deaco $\{27\}$ bamba en Cinco dias del mes demarço $\{28\}$ demill Y seis<cientos> YochentaY seis el Doctor \{29\} Don Melchor decotes Peralta Cura \{30\} Y Vicario del Venefiçio deconaica $\{$ h. 245\} [margen superior: e] $\{1\}$ Vistto estos auttos y de la culpa que deellos $\{2\}$ rresultta Contra Don Juan flores de $\{3\}$ Valdes tenienttegeneral de esta $\{4\}$ prouinçia de los Angaraes hago $\{5\}$ rremiçion deesta causa al ex<celentisimo> Señor $\{6\}$ Duque dela Palatta Virrey de es $\{7\}$ tos paraque Con su vistta proueay mande $\{8\}$ lo que fuere Seruido y lo firme antemi $\{9\}$ A faltta deNottario Siendo testigos $\{10\}$ 
$\mathrm{Ju}<\mathrm{an}>$ delos rrios y Diego de Segouia $\{11\}$ que Se hallaron presenttes $=$ Docttor $\{12\}$ Don Melchor de Cotes Peralta $=$ Juan $\{13\}$ delos rrios $=$ Diego de segouia

\{14\} [margen subrayado: Autto] En el pueblo de San Pedro demoya \{15\} Jurisdiçion dela Prouinçia delos an $\{16\}$ garaes en catorçe dias del mes de $\{17\}$ março demill y seis $<$ cientos> y ochentay seis $\{18\}$ años $=$ El Docttor Don Melchor de $\{19\}$ Cottes Peraltta Curay Vicario de la $\{20\}$ Doctrina de conayca $=$ digo que sin $\{21\}$ embargo de Aver hecho autto derre $\{22\}$ miçion enestta causa es presiso pro $\{23\}$ Seguir enella porquantto evenido $\{24\}$ aestte $\mathrm{d}<\mathrm{ic}>$ ho pueblo porser del $\mathrm{d}<\mathrm{ic}>$ ho mi $\{25\}$ Curatto aconfesar[tachado: los] los Yndios del $\{26\}$ por ttener Notiçia que los Yndios an $\{27\}$ traydo Unos Odres llenos de Vino \{28\} Para que se vendiese Por quenta de \{29\} Don $\mathrm{Ju}<\mathrm{an}>$ flores de Valdes teniente $\{\mathrm{h} .245 \mathrm{v}\}$ [margen superior: e] $\{1\}$ General de la $\mathrm{d}<\mathrm{ic}>$ ha prouincia $\mathrm{Yu}\{2\}$ Sando dela faculttad Suso Citada $\{3\}$ delaprouicion de Veintte de febrero $\{4\}$ en el autto que ba porcauesa mando $\{5\}$ queporsuttenor Se exsamine los ttesti\{6\}gos q<ue> Supieren del caso y asi lo prouei $\{7\}$ Antte mi Juridicamentte afalttade $\{8\}$ Nottario Siendo ttestigos Mattheo $\{9\}$ de leon Garauitto $=y$ D<on $>$ Alexo $\{10\}$ Curiñaupa que se hallaron presentes $\{11\}$ Docttor Don Melchor decottes Peralta $\{12\}$ Mattheo de leon garauitto $=$ Don $\{14\}$ alexo Curiñaupa

$\{15\}$ [margen: Nombra|miento] En el pueblo de Moya en $\mathrm{d}<\mathrm{ic}>$ ho dia $\mathrm{Ca}\{16\}$ torçe de Março demill y seiscientos $\{17\}$ y ochenttay Seis años el Docttor Don \{18\} Melchor decottes Peraltta Curay $\{19\}$ Vicario del Veneficio deconayca $\{20\}$ jurisdicion de Angaraes dijo quepara $\{21\}$ Laprosecuçion deestacausa es neçesario $\{22\}$ Nombrarynterprette porserYn<dios $>\{23\}$ los que ande declarar enella por lo $\{24\}$ qual nombro a Mattheo de leon ga $\{25\}$ rauitto persona ynteligente enla $\{26\}$ lengua delos naturales y estando $\{27\}$ presentte el suso $d<i c>$ ho açetto $d<i c>$ ho nombra $\{28\}$ mientto y juro a Dios y auna Cruz de $\{29\}$ vsar vienY fielmentte $d<i c>$ ho oficio siasi lo $\{30\}$ hiciere Dios leayude y sino Selodemande $\{31\}$ Y dijo Si juro y amen Y lo firmo Con $\{\mathrm{h}$. $246\}\{1\}$ migo [margen superior: e] Y con los ttestigos que se hallaron $\{2\}$ presenttes afaltta de Notario que lo $\{3\}$ fueron Don Alexo Curiñaupa y Pedro $\{4\}$ Poma $=$ Docttor Don Melchor de Cotes $\{5\}$ Peraltta $=$ Mattheo de leon garauito $\{6\}$ Don Alexo Curiñaupa $=$ Pedro Poma

\{7\} [margen: $\mathrm{t}<\mathrm{es}>\mathrm{t}<\mathrm{igo}>\mid$ Don | Alexo | curiñaupa] Enel pueblo de San Pedro de Moya $\{8\}$ jurisdiçion dela prouincia delos anga $\{9\}$ raes enquinçe dias del mes demarço $\{10\}$ demill y seisçienttos y ochentay seis $\{11\}$ años el Docttor Don Melchor decotes \{12\} Peraltta Curay Vicario dela Doctrina $\{13\}$ de conayca para la prosecuçion deesta $\{14\}$ Causa hize pareser ante mi avnYndio $\{15\}$ Ladino en la lengua Castellana y sin $\{16\}$ embargo de serlo por $\mathrm{d}<\mathrm{ic}>$ hayntter $\{17\}$ prettaçion dijo llamarse $\mathrm{D}<$ on $>$ Alexo $\{18\}$ Curiñaupa y serprincipal y Curaca $\{19\}$ deeste $d<i c>$ ho pueblo del qual rreçeui $\{20\}$ juramentto por Dios nuestro Señor $\{21\}$ y auna señal de cruz Segun derecho $\{22\}$ y so cargo del prometio desir verdad $\{23\}$ delo que supiere y le fuese preguntado $\{24\}$ y siendolo Alttenor del autto que bapor $\{25\}$ Cauesa = Dijo este testigo que lo que saue $\{26\}$ es por auerlo Vistto que abra Veinte $\{27\}$ dias Poco mas $\mathrm{O}$ menos que embio a $\{28\}$ auisar Don $\mathrm{Ju}<\mathrm{an}>$ flores de Valdes the $\{29\}$ nientte General deesta Prouinçia 
fuesen $\{$ h. 246v $\}$ [margen superior: e] $\{1\}$ Por Vino de esttepueblo y fue $\{2\}$ $\mathrm{Xp}<$ is $>$ ttoval rrafael y domingo $\{3\}$ Esttevan y ttraxeron dos Odres lle $\{4\}$ nos devino enque dijeron auerquatro $\{5\}$ Votijas las quales serrepartieron a $\{6\}$ lorenço peña alcalde Ordinario $\{7\}$ a $\mathrm{Ju}<\mathrm{an}>$ marca alcalde delcampo a $\{8\}$ Alonso y auri rrejidor y alonso chanca $\{9\}$ paravenderlas porquentta de $d<i c>$ ho $\{10\}$ tenientte arraçon de diez pesos cada $\{11\}$ Votija y queauasiar $\mathrm{d}<\mathrm{ic}>$ ho Vino enlas $\{12\}$ Votijas falttaua para llenar las mas $\{13\}$ No poreso dejan deenterar por cada $\{14\}$ vna $d<i c>h o s$ diez pesos $y$ saue que auido $\{15\}$ Votija queno sale mas que siette pesos $\{16\}$ y medio y que hauiendo auiendo $\{17\}$ auido vna borrachera rriñieron el $\{18\}$ Alcaldey rrejidor y ano auerlo a $\{19\}$ pasiaguado vbiera susedido vna des $\{20\}$ graçia entre ellos y que las mulas $\{21\}$ eYndios que banatraer $\mathrm{d}<\mathrm{ic}>$ ho Vino $\{22\}$ Nunca se les paga el trauajo siendo $\{23\}$ asi queay destepueblo alpueblo de $\{24\}$ acobamba adondelovan atraer diez $\{25\} \mathrm{Y}$ ocho leguas y que en veniendo $\{26\}$ acobrar elyndio queno entera $\{27\}$ Los diez pesos decada Votija lo metten $\{28\}$ enla carzel Y no sale della hasta auer $\{\mathrm{h}$. 247\} [margen superior: e] $\{1\}$ hecho lapaga y saueque cada tercio $\{2\}$ que es de seis en seis meses traen aestepue $<$ blo $>\{3\}$ quatro Votijas de Vino dequentta $\{4\}$ de $d<i c>$ ho ttenientte y aunque estetestigo $\{5\}$ juro en la reçidençia que dio $\mathrm{d}<\mathrm{ic}>$ ho teni $\{6\}$ entte abra dos años queno sevendia $\{7\}$ Vino por suquentta lo hizo porver que $\{8\}$ Otros asian lo mesmo y porque declararlo $\{9\}$ Selepodia Seguir algun perjuicio por $\{10\}$ auer Prosseguido Con la vara demas $\{11\}$ deser alguaçil mayor perpetuo en la $\{12\}$ Villa deguancauelica y que en ttodos $\{13\}$ los pueblos deestaprouinçia Serreparte $\{14\}$ Vino dequentta de $d<i c>$ ho tenientte $\{15\}$ enla conformidad $d<i c>$ ha y esto dijo $\{16\}$ Ser lauerdad So cargo de su juram<ento> $\{17\}$ fecho en que leydo y dado aentender $\{18\}$ por $\mathrm{d}<\mathrm{ic}>$ haYnterpretaçion seafirmo $\{19\}$ y rratifico y dijo ser deedad dequarenta $\{20\}$ y seis años poco mas $\mathrm{O}$ menos y lo firmo $\{21\}$ Conmigo y Con los testigos Conquien $\{22\}$ actuo por faltta denotario quelo fue $\{23\}$ ron Pedro Poma y Pedro ChapaY $\{24\}$ $\mathrm{d}<\mathrm{ic}>$ ho Ynterprette $=$ Docttor Don $\{25\}$ Melchor decotes Peraltta $=$ Don Alexo $\{26\}$ Curiñaupa $=$ Matheo de leon garauito $\{27\}$ Pedro Poma $=$ Pedro Chapa

\{28\} [margen: $\mathrm{t}\langle\mathrm{es}>\mathrm{t}\langle$ igo $>|$ Lorenço | Pena] Enelpueblo demoya de la Prouinçia de $\{29\}$ Los angaraes end $<\mathrm{ic}>$ ho dia quinçe demarço $\{\mathrm{h} .247 \mathrm{v}\}$ [margen superior: e] $\{1\}$ deMill y seiscienttos y ochentaY $\{2\}$ Seis años = El Docttor Don Melchor $\{3\}$ de Cottes Peraltta Curay Vicario de $\{4\}$ la Doctrina deconaica para laprosecu $\{5\}$ çion deesta causa hizepareçer antemi $\{6\}$ avnyndio que por $d<i c>$ haynterpretaz $<$ ion $>\{7\}$ dijo llamarse Lorenço peña y ser al $\{8\}$ calde hordinario deeste dicho pueblo $\{9\}$ del qual rreçeui juramento por $\{10\}$ Dios nuestro Señor y auna señal $\{11\}$ decruz Segunderecho y so cargo del $\{12\}$ promettio desir verdad y delo que $\{13\}$ supierey le fuese preguntado y $\operatorname{sien}\{14\}$ dolo al tenor delacauesadeprosesso $=$

$\{15\}$ Dijo estte testigo que saue que $\mathrm{Xp}<\mathrm{is}>\operatorname{to}\{16\}$ val rrafael y Domingo esteuan $\{17\}$ fueron alpueblo de acobamba abra $\{18\}$ Veintte dias atraer Vino dequenta $\{19\}$ del tenientte general Don Juan $\{20\}$ flores de Valdes y que trajeron dos $\{21\}$ odres llenos de vino parauenderlos \{22\} Por suquentta arraçon de diez pesos \{23\} Cada Votija y queaeste testigo Como $\{24\}$ tal Alcalde letoco vnay las demas Se $\{25\}$ rrepartieron a 
$\mathrm{Ju}<\mathrm{an}>$ marca alcalde $\{26\}$ del campo a Alonso Y auri rrejidor $\{27\}$ y a Alonso Chanca yquedecada Votija $\{28\}$ No sale mas q<ue $>$ siette pesos y medio y cada $\{$ h. 248\} [margen superior: e] $\{1\}$ Año Serrepartten porquentta de $d<i c>$ ho $\{2\}$ ttenientte enestte pueblo Ocho votijas $\{3\}$ deVino y en estta Conformidad en $\{4\}$ los demas Pueblos de esta jurisdiçion $\{5\}$ y queno seles paga $\mathrm{Su}$ trauajo $\mathrm{A} \operatorname{los}\{6\}$ Yndios que ban por $\mathrm{d}<\mathrm{ic}>$ ho Vino ni menos $\{7\}$ las mulas que lo traen y quando $\{8\}$ Vienen alacobrança alqueno $\{9\}$ da los diez pesos lo metten enla car $\{10\}$ zel y no sale deella hastta quepague $\{11\}$ y estto dijo Ser lauerdad So cargo $\{12\}$ desujuramentto fecho enque leydo $\{13\}$ y dado a entender seafirmo y rratifico $\{14\}$ y dijo ser deedad decinquentta años $\{15\}$ Poco mas $O$ menos no firmo porquedijo $\{16\}$ No sauer firmelo yo Con $\mathrm{d}<\mathrm{ic}>$ ho ynter $\{17\}$ prette y testigos a faltta denotario $\{18\}$ que lo fueron Pedro Poma y Pedro $\{19\}$ Chapa $=$ que se hallaron presenttes $\{20\}$ Docttor Don Melchor decotes Peralta $\{21\}$ Mattheo de Leon garauitto $=\operatorname{Pe}\{22\}$ dro Poma $=$ Pedro Chapa

$\{23\}$ [margen: $\mathrm{t}<\mathrm{es}>\mathrm{t}<\mathrm{igo}>\mid$ Juan $\mid$ Marca] Enel pueblo de San Pedro demoya $\{24\}$ dela Prouinçia delos angaraes $\{25\} \mathrm{d}<\mathrm{ic}>$ ho dia quinçe demarço demill $\{26\}$ y seiscientos Yochenttay Seis años \{27\} El Docttor Don Melchor decotes Peralta $\{28\}$ curaY Vicario del venefiçio deconaica $\{$ h. 248v $\}$ [margen superior: e] $\{1\}$ Para la prosecucion de estta causa hizepa $\{2\}$ reçer Antte mi avnyndio quepor $\{3\} \mathrm{d}<$ ic $>$ hayntterpretaçion $=$ Dijo llamarse $\{4\}$ Juan marca y ser alcalde delcampo $\{5\}$ del qual reçeui juramento por Dios $\{6\}$ nuestro Señor y auna Señal decruz $\{7\}$ Segun forma dederecho y so cargo $\{8\}$ delprometio desir verdad delo $\{9\}$ que supierey le fuesepregunttado $\{10\}$ y siendolo altenor dela cauesa depro $\{11\}$ çesso que le fueleyda $=$ dijo este tes $\{12\}$ tigo que saue por auerlo visto que $\{13\}$ abraVeintte dias que fue $\mathrm{Xp}<\mathrm{is}>$ toval $\{14\}$ rrafaely Domingo esttevan al $\{15\}$ pueblo de Acobamba a traer elvino $\{16\}$ queserreparte enestte pueblo por $\{17\}$ quentta deDonJu<an> flores deval $\{18\}$ des ttenienttegeneral deesttapro $\{19\}$ vinçia y auiendo llegado trajeron $\{20\}$ dos odres llenos y a este testigo le $\{21\}$ dieron Vna botija para quelaven $\{22\}$ diese y las demas a lorenço Peña $\{23\}$ Alcalde hordinario deestepueblo $\{24\}$ a Alonso Y auri rrejidor y a alonso $\{25\}$ Chanca haçiendoles Cargo porcada \{26\} Votija adiez pesos y porestar algo \{27\} bacia la votija y ser pequeña $\{28\}$ No saco este testigo mas de siettepesos $\{$ h. 249\} [margen superior: e] $\{1\}$ Y medio mas no poreso dejara $\{2\}$ depagar dichos diez pesos Por $\{3\}$ que le apremiaran a ello $\{4\} \mathrm{Y}$ aoradias enttre el alcalde $\{5\}$ Ordinay rrexidor vbo penden $\{6\}$ cia por auerse embriagado $\{7\}$ Con $d<i c>$ ho Vino y ano auerlos $\{8\}$ Metido en pas vbiera $\mathrm{Su}\{9\}$ çedido alguna desgraçia $\mathrm{Y}\{10\}$ que a los Yndios que ban $\{11\}$ a traer dicho vino ni las $\{12\}$ Mulas que lo cargan Se les $\{13\}$ paga auiendo mas devein $\{14\}$ tte Leguas y que cada año $\{15\}$ Serrepartten en este pueblo $\{16\}$ Ocho Votijas devino quatro \{17\} Cada Seis meses y la mesma $\{18\}$ Cantidad encada Pueblo $\{19\}$ deestaJurisdicion y en $\{20\}$ Cumpliendose el ttermino $\{21\}$ los metten en la Carzel Yno $\{22\}$ Salen deella hastta auer $\{23\}$ pagado lo qual han hecho $\{24\}$ ttodos Los tthenientes Y es $\{25\}$ to dijo Ser laverdad So $\{26\}$ Cargo desujuramentto $\{\mathrm{h}$. 249v [margen superior: e] $\{1\}$ fecho en que leydo Seafirmo $\{2\}$ y rratifico y dijo Ser deedad \{3\} demas dequarentta años $\{4\}$ No firmo porque dijo No $\{5\}$ Sa[tachado: ue]ver firmelo yo Con $\mathrm{d}<\mathrm{ic}>$ ho $\{6\}$ yntterprette Siendo testigos $\{7\}$ Pedro Poma y Pedro chapa 
$\{8\}$ Docttor Don Melchor decotes $\{9\}$ Peraltta $=$ Mattheo de leon $\{10\}$ Garauitto $=$ Pedro Poma $\{11\}$ Pedro chapa

\{12\} [margen: $\mathrm{t}<\mathrm{es}>\mathrm{t}<\mathrm{igo}>\mid \mathrm{Xp}<$ is $>$ toval $\mid$ rrafael] En el pueblo de San Pedro de $\{13\}$ Moya jurisdiçion dela Pro $\{14\}$ vincia delos angaraes en $\{15\}$ dicho dia quinçe demarço $\{16\}$ demill y seiscientos y ochen $\{17\}$ ttay seis años $=$ el Docttor Don $\{18\}$ Melchor de cottes peraltta Cura $\{19\}$ y Vicario del venefiçio de $\operatorname{Co}\{20\}$ nayca para la prosecuçion $\operatorname{des}\{21\}$ tta causa hizepareser antte $\{22\} \mathrm{mi}$ avnYndio quepor di $\{23\}$ chaYntterpretaçion dijo lla $\{24\}$ marse $\mathrm{Xp}<$ is $>$ toval rrafael $\{25\}$ Y ser natural deestte dicho \{26\} Pueblo del qual rreçeui $\{$ h. 250\} [margen superior: e] $\{1\}$ juramentto por dios nuestro $\{2\}$ Señor y auna Señal decruz $\{3\}$ Segun derecho y So cargo del $\{4\}$ promettio deçirverdad de $\{5\}$ lo que supiere y le fuesepre $\{6\}$ gunttado y siendolo alttenor $\{7\}$ de la cauesa de prozeso que le $\{8\}$ fue Leyda = dijo este testigo $\{9\}$ que abra mas de Veinte dias $\{10\}$ que fue al pueblo deacobamba $\{11\}$ en compañia deDomingo $\{12\}$ Esttevan a traer dos odress $\{13\}$ llenos devino que le entre $\{14\}$ go el tenientte general $\{15\}$ de estta prouinçia Don $\mathrm{Ju}<\mathrm{an}>\{16\}$ flores de Valdes paraque $\{17\}$ los entregase enestepueblo $\{18\}$ a los mandones y sevendiesen $\{19\}$ Por su quentta y auiendo $\{20\}$ traydo $Y$ entregado Serre $\{21\}$ parttio vna botija al alcalde $\{22\}$ Ordinario y las demas al $\{23\}$ alcalde delcampo al rre $\{24\}$ jidor y a alonso Chanca Ysa $\{25\}$ vequepagan porcadavotija $\{26\}$ a diez pesos y cada año Serre $\{$ h. 250v $\}\{1\}$ Partten [margen superior: e] ocho y queno se lepago \{2\} Su trauajo ni el delas Mu\{3\}las que lleuo pordesiresta en \{4\} Costumbre auiendo veinte $\{5\}$ leguas de camino y que en $\{6\}$ los demas pueblos se haçe la $\{7\}$ mesma rreparticion y quan $\{8\}$ do vienen a lacobrança el $\{9\}$ Yndio queno da la platta $\{10\}$ lo ponen en la carzel y no $\{11\}$ sale deella sin queayapa $\{12\}$ gado y esto dijo ser lauer $\{13\}$ dad So cargo desujuramen $\{14\}$ tto fecho enque leydo Sea $\{15\}$ firmo y rratifico y dijo ser $\{16\}$ deedad dequarentay ocho $\{17\}$ años poco mas $O$ menos No $\{18\}$ firmo porque dijo No sauer $\{19\}$ firmelo yo Con dicho Ynter $\{20\}$ prette y testigos a faltta de $\{21\}$ Nottario que lo fueron $\{22\}$ Pedro chapa presenttes $=$

$\{23\}$ Docttor Don melchor decotes $\{24\}$ Peraltta $=$ Matheo de leon $\{25\}$ garauitto $=$ Pedro Chapa $\{26\}$ Pedro Poma

\{h. 251\} [margen superior: e] $\{1\}$ [margen subrayado: Autto] Enel pueblo de sanpedro de $\{2\}$ moya jurisdicion dela prouin $\{3\}$ çia delos angaraes enquinçe $\{4\}$ dias del mes demarço demill $\{5\}$ y seiscienttos y ochentay seis $\{6\}$ años el Docttor Don Melchor $\{7\}$ de cottes Peraltta Cura y Vi $\{8\}$ cario del venefiçio deconaica $\{9\}$ hago rremiçion destos autos $\{10\}$ al excelentisimo Señor $\{11\}$ Duque dela palatta Vi $\{12\}$ rrey de estos rreynos para $\{13\}$ que Convistta de ellos $\operatorname{man}\{14\}$ de lo que fuere seruido $Y$ lo $\{15\}$ firme anttemi juridicamente $\{16\}$ a faltta de Notario Siendo $\{17\}$ testigos Mattheo de leon $\{18\}$ garauitto $=\mathrm{y}$ Don Alexo $\{19\}$ Curiñaupa que se hallaron $\{20\}$ presenttes = Docttor Don $\{21\}$ Melchor de cottes Peralta $\{22\}$ Mattheo de leon gara $\{23\}$ vitto $=$ Don Alexo Curi $\{24\}$ ñaupa

$\{25\}$ [margen: Nombra|mi<ento> de | Ynter|pre] En lauilla deguancauelica $\{26\}$ en seis dias del mes de Junio $\{27\}$ demill $\mathrm{Y}$ seis[**]entos $\mathrm{Y}$ ochenta $\{\mathrm{h} .251 \mathrm{v}\}$ [margen 
superior: e] $\{1\}$ Y seis años el Señor Docttor Don $\{2\} \mathrm{Ju}<\mathrm{an}>\mathrm{Lusi}$ Lopez del Consejo de su $\{3\}$ Magesttad Alcalde decortte $\{4\}$ mas antiguo delarreal $\{5\}$ audiençia de los rreyes Go $\{6\}$ vernador de estta dichauilla $\{7\}$ Su cerro y mina rreal deacogue $\{8\}$ Correxidor y Justiçia ma $\{9\}$ yor dela prouincia delos an $\{10\}$ garaes thenientte de capittan $\{11\}$ General en sus distrittos y al $\{12\}$ calde mayor de minas = Dijo $\{13\}$ que Por quantto en esta causa $\{14\}$ Sean de exsaminar Yndios $\{15\}$ y Conviene Nombraryntter $\{16\}$ prette dela Lengua $\mathrm{Y}$ porque en $\{17\}$ lapersona de Joseph desotto $\{18\}$ mayor Concurren las parttes $\{19\}$ Necesarias desde luego Sumerced $\{20\}$ Lenombra porttalyntterprete $\{21\}$ al qual se le notifique Lo açette $\{22\}$ y jure y sumerçed lo rrubriço $\{23\}$ antte mi miguel de cantoral $\{24\}$ escriuano de su $\operatorname{Mag}<\operatorname{estad}>$

\{25\} [margen: $\mathrm{N}<$ ombramiento $>$ acetaz<ion> | $\mathrm{Y}$ juram<ento>] En lauilla deguancauelica $\{26\}$ en seis de Junio del $d<i c>$ ho año $\{27\}$ Yo el escriuano hize Sauer $\{28\}$ el nombramientto dearriua $\{$ h. 252\} [margen superior: e] $\{1\}$ a Joseph de sottomayor Alcalde $\{2\}$ mayor de esttauilla el nombra $\{3\}$ mientto deYntterprette $\{4\}$ en estta causa el qual dixo $\{5\}$ que lo açettabaY juro a Dios $\{6\}$ y avna Señal decruz haçer $\{7\}$ Vieny fielmentte el dicho $\{8\}$ Oficio Si ansi lo hiçiere Dios le $\{9\}$ ayude y sino se lo demande Y $\{10\}$ dijo si juro Y amen Y lo firmo $\{11\}$ Joseph. De Sotto mayor = Miguel $\{12\}$ de canttoral escriuano de su mag<estad> $\{13\}$ Ynformaçion fecha de Oden del $\{14\}$ excelentisimo Señor Duque $\{15\}$ dela palatta Virrey de estos $\{16\}$ rreynos

$\{17\}$ [margen: $t<e s>t<$ igo $>\mid$ Don $\mid$ Alejo | curiñaupa] En lauilla deguancauelica en $\{18\}$ Seis dias del mes de Junio $\{19\}$ demill seiscienttos y ochenta $\{20\}$ Y seis años el Señor Docttor \{21\} Don Ju<an> Luis Lopez del Consejo \{22\} desu Mag<estad> alcalde decortte mas $\{23\}$ Antiguo dela rreal audiençia $\{24\}$ dela Çiudad delos rreyes $\{25\}$ Governador deestauilla deguan $\{26\}$ cauelica Correxidor y justicia $\{27\}$ mayor dela Prouincia delos $\{$ h. 252v\} [margen superior: e] $\{1\}$ Angaraes hizo pareçer antte si a $\{2\}$ Don Alejo Curiñaupa Curaca del $\{3\}$ pueblo demoya de dicha prouinçia $\{4\}$ del qual su merçed poryntterpre $\{5\}$ ttaçion delyntterprette nombra $\{6\}$ do rreçiuio juramentto y le hizo $\{7\}$ por Dios nuestro Señor y auna $\{8\}$ Señal de cruz Y auiendole fecho $\{9\}$ Promettio dedeçir verdad Y sien $\{10\}$ do pregunttado al ttenor del auto $\{11\}$ que ba por cauesa proueydo por su $\{12\}$ Merçed = dijo que estte testigo tiene $\{13\}$ dicho su dicho en rraçon delo $\{14\}$ Conttenido enel $\mathrm{d}<\mathrm{ic}>$ ho autto ante $\{15\}$ el Docttor Don Melchor de cottes $\{16\}$ Peraltta Cura y Vicario dela Do $\{17\}$ ctrina de conaica de dicha pro $\{18\}$ vincia y pidio Sele leay muestre $\{19\}$ Yo el escriuano Sele ley Y auien $\{20\}$ dole Oydo y entendido = dijo que $\{21\}$ el dicho Cura y Vicario llamo aeste $\{22\}$ ttestigo a su casa Y le dijo que firmara $\{23\}$ la declaracion y dicho que tenia $\{24\}$ escritto y estte testigo Sin sauer $\{25\}$ lo que firmaua firmo la firma $\{26\}$ que estta alpie del dicho dicho que $\{27\}$ rreconoçe Por suya $Y$ que el auer $\{$ h. 253$\}$ [margen superior: e] $\{1\}$ firmado fue de miedo del dicho $\{2\}$ Cura y que lo que pasa es $Y$ seacos $\{3\}$ tumbrado en el $\mathrm{d}<\mathrm{ic}>$ ho pueblo $\{4\}$ de Moya demuchos años aestta $\{5\}$ partte es que los tenienttes quean $\{6\}$ sido de la dicha prouinçia an $\{7\}$ embiado al $d<$ ic $>$ ho pueblo quatro $\{8\}$ Votijas de vino cada seis Meses $\{9\}$ por pedirlas el dicho pueblo eYn<dios $>\{10\}$ deel 
para sus neçesidades Onrras \{11\} Casamienttos y Bautismos Y para $\{12\}$ las misas quese disen en la Ygleçia $\{13\}$ del dicho pueblo y para despachar $\{14\}$ los Yndios dela rroça quevienen $\{15\}$ A trauajar a estta rreal mina $\{16\}$ para animarlos aquevengan $\{17\}$ al trauajo $Y$ en faltando los yn<dios $>\{18\}$ an emuiado adeçir alos dichos te $\{19\}$ nienttes les emuien Vino No pasan $\{20\}$ do Nunca del numero delas d $<$ ic $>$ has \{21\} quatro Votijas cada seis meses No \{22\} Saue estte testigo aya auido vio\{23\}lençia por Don $\mathrm{Ju}<a n>$ flores $\{24\}$ ttenienttegeneral actual ni sus $\{25\}$ anteçesores en la rrepartiçion $\{26\}$ del dicho Vino porserles alos $\mathrm{Yn}<\mathrm{dios}>\{27\}$ dela Combeniençia que tiene rre $\{28\}$ ferida $\mathrm{Y}$ que es verdad que porcada $\{\mathrm{h} .253 \mathrm{v}\}$ [margen superior: e] $\{1\}$ Votija Seapagado acada teniente $\{2\}$ a diez pesos y le Constta aeste testigo $\{3\}$ que las yndias que lo menudean $\{4\}$ Sacan treze y catorçepesos de cada $\{5\}$ Votija y Como tal curaca Saue $\{6\}$ que algunos Yndios del $d<i c>$ ho pue $<$ blo $>\{7\}$ tenien por grangeria traervino $\{8\}$ delos llanos y lo venden sin que $\{9\}$ nadie Selo ympida y quequanto $\{10\}$ alo quecontiene el dicho que se le $\{11\}$ a leydo deque a auido Votija queno $\{12\}$ Sale deella mas que siette pesos y me $\{13\}$ dio es siniestro y no adeclarado $\{14\}$ tal cosa porque Como $d<i c>$ ho tiene $\{15\}$ Sale de cada votija a trezey a catorze $\{16\}$ pesos $Y$ enquantto ala pendençia $\{17\}$ que rrefiere el $\mathrm{d}\langle\mathrm{ic}>$ ho dicho $=$ Dijo $\{18\}$ que es verdad que elalcaldey rre $\{19\}$ jidor del dicho pueblo tubieron $\{20\}$ enquentro Sobre las jurisdiçiones $\{21\}$ No saue estte testigo si estauan borra $\{22\}$ chos Uno porque este testigo No $\{23\}$ Se hallo presentte al enojo $\{24\}$ que tuuieron Yotro dia por la $\{25\}$ mañana tubo notiçia este testigo $\{26\}$ de la $\mathrm{d}<\mathrm{ic}>$ ha pendençia $=$ Yenquanto $\{27\} \mathrm{A}$ lapaga del flette de la mula $\{28\}$ Y trauajo delYndio que ba $\{29\}$ Por el dicho Vino es verdad \{h. 254\} [margen superior: e] $\{1\}$ No sepaga nada de la $d<i c>$ ha trayda por $\{2\}$ Sacarse de cada Votixa la cantidad que $\{3\}$ tiene declarado y quedarse los Yndios $\{4\}$ Con el casco de las Votixas vacias $=$

\{5\} Y que en quantto A lo querrefiere $\{6\}$ el dicho dicho deque elyndio queno $\{7\}$ entera Los diez pesos decada Votixa $\{8\}$ lo metten en la carzel y queno sale $\{9\}$ deella hastta auer hecho lapaga lo $\{10\}$ quepassa enestto es que elyndio $\{11\}$ que tiene a su cargo laventa del $\mathrm{d}<\mathrm{ic}>$ ho $\{12\}$ Vino quando vienen acobrarlo dize $\{13\}$ alapersona que Viene aello que lepren $\{14\}$ dan en la carzel para poder Cobrar $\{15\}$ de las personas aquien lo afiado $\{16\}$ y destta manera Seacobrado Sin $\{17\}$ que se dettenga el Yndio en la car $\{18\}$ zel vn dia porque Con esta aparien $\{19\}$ çia Cobran lo que anfiado y que en $\{20\}$ quantto aque el dicho Don Juan $\{21\}$ flores rrepartia vino en los demas $\{22\}$ Pueblos lo tiene asi entendido $\{23\}$ Y lo rreçeuiran los pueblos para los $\{24\}$ efecttos que lo arreçeuido el dicho $\{25\}$ pueblo de moya y estto es en los pue $\{26\}$ blos deconaica Cuencay Vilcabamba $\{27\}$ Y delos demas no saue nada = Yen $\{28\}$ quantto alo que dice el dicho dicho $\{29\}$ deque el $\mathrm{d}<\mathrm{ic}>$ ho Don Juan flores $\{\mathrm{h} .254 \mathrm{v}\}$ [margen superior: e] $\{1\}$ Embio auisar al dicho pueblo para $\{2\}$ que fuesen porvino es costumbre em $\{3\}$ biar los yndios porello de seis aseis me $\{4\}$ ses para las Necesidades que tiene $\{5\}$ rreferido eldicho dicho fueron $\{6\} \mathrm{Xp}<$ is $>$ toval rrafael y Domingo $\{7\}$ Esttevan y trujeron En dos odres $\{8\}$ las $\mathrm{d}<\mathrm{ic}>$ has quatro Votixas devino $\{9\}$ las quales Sedieron alorenço $\{10\}$ Peña alcalde Ordinario a Juan $\{11\}$ Marca alcalde del campo a alonso $\{12\}$ y auri Rejidor y a alonso Chanca $\{13\}$ Para quelas vendiesen libremen $\{14\}$ tte Sin 
forçar anadie Lo comprase $\{15\}$ anttes es vtil elvender el dicho $\{16\}$ Vino porlo que tiene dicho y esto $\{17\}$ dijo ser lauerdad So cargo del $\{18\}$ juramentto que tiene fecho $\{19\}$ enque se afirmo y rratifico $Y$ lo $\{20\}$ firmo y dijo ser deedad de qua $\{21\}$ renttay seis años Y que aunque $\{22\}$ es curaca del dicho pueblo No poreso $\{23\}$ a dejado de decir laverdad y sumer $\{24\}$ çed lo rrubrico $Y$ firmo el $d<$ ic $>$ ho $\mathrm{Yn}\{25\}$ tterprette, Y su merçed lo señalo $\{26\}$ Don Alexo Curiñaupa $=$ Joseph de $\{27\}$ Sotto mayor antte mi Miguel $\{28\}$ decantoral escriuano de suMag<estad>

\{h. 255\} [margen superior: e] $\{1\}$ [margen: $\mathrm{t}<\mathrm{es}>\mathrm{t}<$ igo $>\mid$ thomas $\mid$ quispe] en lauilla deguancauelica en $\{2\}$ Seis dias del mes de Junio demill $\{3\}$ Y seiscienttos y ochentta $Y$ seis años $\{4\}$ el $d<i c>$ ho Señor governador Para $\{5\}$ la $d<i c>$ ha aueriguacion hiço parezer $\{6\}$ Antte si a tomas quispe Yndio $\{7\}$ del pueblo de Vilcabamba que de $\{8\}$ claro antte el Doctor Don melchor $\{9\}$ decottes Peraltta Curay Vicario $\{10\}$ dela Doctrina deconayca del qual $\{11\}$ Por la dichayntterpretaçion fue $\{12\}$ rreceuido juramento y le hizo por $\{13\}$ Dios nuestro Señor y auna Señal $\{14\}$ de cruz y prometio de decir verdad $\{15\}$ y siendo pregunttado Al ttenor $\{16\}$ del autto por su merçed su Proveydo $\{17\}$ Dijo que tiene dicho su dicho $\{18\}$ antte el dicho Vicario Sobre $\{19\}$ lo conttenido en dicho autto $\{20\}$ y pidio Sele lea eyo el escriuano $\{21\}$ Se le ley Y hauiendole [tachado: mostrado] \{22\} Oydo y enttendido Dijo que \{23\} Como es Costumbre rreçiuio en $\{24\}$ el dicho Pueblo devilcabam $\{25\}$ ba donde este testigo rreçide Siete $\{26\}$ Votijas devino dequentta de Don $\{27\} \mathrm{Ju}<\mathrm{an}>$ flores de Valdes teniente $\{28\}$ General de dicha Prouinçia de $\{\mathrm{h} .255 \mathrm{v}\}$ [margen superior: e] $\{1\}$ Angaraes y esttas fueron Por ttodo $\{2\}$ el año que fue estte ttestigo Alcalde $\{3\}$ del campo para que en $\mathrm{d}<\mathrm{ic}>$ ho pueblo $\{4\}$ Sus Conttornos y punas lo dispendiese $\{5\} \mathrm{Y}$ siruiese para sus Necesidades Sin $\{6\}$ que el dicho tenientte le obligasse $\{7\}$ a lleuarlo Aotras parttes auender $\{8\}$ y que se lo pone para las Necesidades $\{9\}$ que sepueden Ofreçer en dicho $\{10\}$ pueblo Sin que le aya hecho $\{11\}$ Violencia en rreceuirlo $=Y$ en $\{12\}$ quantto a lo que dize el dicho $d<i c>h o\{13\}$ deque trayendo dicho vino Se le $\{14\}$ auia despeñado vna mula y se $\{15\}$ perdio el $d<$ ic $>$ ho Vino lo quepasa $\{16\}$ es queno esttando estte testigo $\{17\}$ en el dicho Pueblo devilcabam $\{18\}$ ba maria rroça Su muger Cargo $\{19\}$ el vino en vna mulay los odres $\{20\}$ enque estaua queriendo lleuar $\{21\}$ lo avnYnJenio Nombrado \{22\} acobamba que estta Çinco leguas $\{23\}$ del dicho pueblo de Vilcabam $\{24\}$ ba por hauer grangeria deello $\{25\}$ en el Camino Se le despeño la $\{26\}$ mula en que lo lleuaba y seperdio $\{27\}$ El dicho Vino y porauer tenido $\{28\}$ la culpa la dicha Su muger dela \{h. 256\} [margen superior: e] $\{1\}$ Perdida del dicho Vino estte tes $\{2\}$ tigo no dixo nada al dicho tenien $\{3\}$ tteGeneral Don Juan flores $\{4\}$ Y lepago por Enttero el dicho vino $\{5\}$ adiez pesos porcada Votixa y las $\{6\}$ despeñadas No fueron mas que $\{7\}$ tres y Enquantto a los Odres $\{8\}$ de vino que rrefiere el dicho $\{9\}$ dicho aver vistto en casa de $\{10\}$ thomas Luis lo que uio No fue mas $\{11\}$ quevn odre Solo que auria Votixa $\{12\}$ y media de Vino y No Otra cosa $=$

$\{13\}$ y que en el dicho Pueblo de vilca $\{14\}$ bamba todas las personas quequie $\{15\}$ ren asi Yndios Como españoles $\{16\}$ Venden vino menudeado tra\{17\}yendo de los Valles por suquenta $\{18\}$ y que es Comida delos yndios $\{19\}$ del dicho pueblo y sus Contornos 
$\{20\}$ el queayauino para las Neçesi $\{21\}$ dades que se ofreçen y porser ca $\{22\}$ mino rreal para la Ciudad $\{23\}$ de los rreyes Y otras parttes Yesto $\{24\}$ Dijo ser lauerdad socargo del $\{25\}$ juramentto que tiene fecho en $\{26\}$ que se afirmo y rratifico $Y$ lo firmo $\{27\} \mathrm{Y}$ dijo ser de edad demas de treinta $\{$ h. 256v $\}$ [margen superior: e] $\{1\}$ años Y queno le tocan las $\{2\}$ generales y Su merçed lo $\{3\}$ rrubrico y firmo el dicho $\{4\}$ yntterprette $=$ thomas quispe $\{5\}$ Joseph de Sottomayor $=$ an $\{6\}$ ttemi Miguel de Canttoral $\{7\}$ Escriuano de su magestad

\{8\} [margen: $\mathrm{t}<\mathrm{es}>\mathrm{t}<$ igo $>\mid$ thomas $\mid$ Luis] En lauilla deguancauelica $\{9\}$ en siette dias del mes de Junio $\{10\}$ demill y seiscientos y ochenta $\{11\}$ y seis años el $d<$ ic $>$ ho Señor go $\{12\}$ vernador para la auerigua $\{13\}$ çion delo Conttenido enel $\{14\}$ autto de su merçed que bapor $\{15\}$ Cauesa hizo parezer ante si avn $\{16\}$ yndio queporYntterpreta $\{17\}$ çion de Joseph de sottomayor $\{18\}$ yntterprette Nombrado = Dijo $\{19\}$ llamarse thomas Luis y Ser $\{20\}$ Natural del Pueblo de vilca $\{21\}$ bamba de la prouinçia delos $\{22\}$ Angaraes del qual Su merced $\{23\}$ por anttemi el escriuano Y $\{24\}$ pordichaYntterpretacion $\{25\}$ rreçeuio juramentto y le hizo $\{26\}$ Por Dios Nuestro Señor $\{$ h. 257\} [margen superior: e] $\{1\} Y$ auna Señal decruz en forma $\{2\}$ dederecho y promettio dezir $\{3\}$ Verdad y siendo preguntado $\{4\}$ Alttenor del dicho autto $=$ dijo $\{5\}$ que este testigo tiene dicho vn $\{6\}$ dicho y declaraçion ante $\{7\}$ el Docttor Don melchor decotes $\{8\}$ Peraltta Curay Vicario de la $\{9\}$ Doctrina deconayca y pidio sele $\{10\}$ leay muestre eyo elescriuano $\{11\}$ Se le Ley Y di aenttender por $\{12\}$ dicho yntterprette y auiendole $\{13\}$ Oydo y entendido $=$ Dijo que $\{14\}$ Siendo este testigo alcalde $\{15\}$ del campo en elynxenio de $\{16\}$ acobamba Se çelebro la fiesta $\{17\}$ desan Joseph el alcalde del $\{18\}$ pueblo de Vilcabamba le em $\{19\}$ Vio adeçir aestte testigo que em $\{20\}$ viasepor el vino rrespecto deque $\{21\}$ tenian fiesta en el dicho ynje $\{22\}$ nio laqual dicha fiesta Se çelebro $\{23\}$ tres dias anttes decarnestolendas $\{24\}$ de esttepresentta año y este testigo $\{25\}$ dijo al $\mathrm{d}<\mathrm{ic}>$ ho Curay Vicario que $\{26\}$ esttaua alli en la Ocaçion para $\{27\}$ Celebrar dicha fiestta Como Ybapor $\{$ h. 257v\} [margen superior: e] $\{1\}$ El vino del tenientte general que le $\{2\}$ diese licençia para ello y el dicho $\{3\}$ Cura le dijo que fuese norabuena $\{4\}$ porello y que en trayendolo le auisase $\{5\}$ Y estte testigo fue al pueblo de vilca $\{6\}$ bamba y vn curaca del le entrego $\{7\}$ quatro Votixas las tres trujo al $\mathrm{d}<\mathrm{ic}>$ ho $\{8\}$ asientto y vna dejo en el dicho pue $\{9\}$ blo para lo que en el seofreciere y aui $\{10\}$ endo llegado al dicho asiento Sin $\{11\}$ auerle dado lugar los Yndios que $\{12\}$ en el auia para auisar al dicho cura $\{13\}$ le cojieron el $d<i c>$ ho Vino y entre e $\{14\}$ llos le rrepartieron quedando solo $\{15\}$ Votijay media y en estta Ocaçion $\{16\}$ llego el dicho vicario y dijo aestte $\{17\}$ ttestigo No te dije quequando $\{18\}$ Voluieses Conelvino me auisases $\{19\}$ Como as empesado adespenderlo ${ }^{2}\{20\}$ y lerrespondio este testigo que los $\{21\}$ dichos Yndios No le auian dado \{22\} lugar a avisarle porque Violenta\{23\}mentte lequitaron elvino que $\{24\}$ faltaua de dichas tres Votixas $\{25\}$ y el dicho Cura hiço cargar elvino $\{26\}$ que auia quedado que eravotixa $\{27\}$ y media $Y$ lo hiço lleuar acasa de $\{28\}$ Mattheo desegouia y que las dichas $\{29\}$ quatro Votixas eran Para Seis $\{\mathrm{h}$. $258\}$ [margen superior: e] $\{1\}$ Meses y en la dicha fiesta Ubo $\{2\}$ muchas rrecatonas

\footnotetext{
${ }^{2}$ Este fragmento debe interpretarse como discurso directo e interrogativo: ¿No te dije quequando Voluieses Conelvino me auisases? ¿Como as Empesado adespenderlo?
} 
quevendian $\{3\}$ Vino y aguardientte Por suquen $\{4\}$ tta y auiendo acudido attener $\{5\}$ estta grangeria para ellas por $\{6\}$ auer ttenido Notiçia dela dicha $\{7\}$ fiestta y que el dicho tenienttege $\{8\}$ neral No les hizo ninguna Vio $\{9\}$ lençia para rreceuir el dicho $\{10\}$ Vino y elauerydo porel fue $\{11\}$ por auerle auisado el dicho $\{12\}$ Alcalde de Vilcabamba fuese $\{13\}$ porel mediantte la dicha fiestta $\{14\}$ y los $d<i c>$ hos Yndios que seauian jun $\{15\}$ tado aella le fomentaron $\mathrm{y}$ rro\{16\}garon que fuesey asido Costum $\{17\}$ bre el dar los tenientes que $\{18\}$ an çido de dicha prouinçia el dar $\{19\}$ algun Vino para las Necesidades $\{20\}$ de los Yndios y sus fiestas Bautismos $\{21\}$ Casamienttos honrras y entierros $\{22\}$ aquien se apagado porcada Votija $\{23\}$ a diez pesos siendo Cierto y Verdad \{24\} que Vendida cada Votixa Me\{25\}nudeada Se sacan Once y dozepesos $\{26\}=\mathrm{Y}$ en quanto alo quedize el dicho $\{27\} \mathrm{Y}$ declaracion de este testigo deque $\{28\}$ el dicho Vino le tenia envna casa $\{h .258 \mathrm{v}\}$ [margen superior: e] \{1\} En el dicho asientto de acobamba $\{2\}$ No fue asi Sino lo que tiene dicho $\{3\}$ y declarado y saue que el dicho $\{4\}$ tenientte y sus antteçesores anrre $\{5\}$ partido vino por las neçesidades $\{6\}$ delos pueblos lo qual asido Vso y $\{7\}$ Costumbre Sin quitar niympedir $\{8\}$ anadie asi [tachado: a] yndios Como españo $\{9\}$ les el quevendan Vino por suq<uenta> $\{10\}$ Porque an dejado libre el trato $\{11\}$ [margen: signo] Y enquantto a lo que esta en dicho $\{12\}$ dicho deque quando Se cobra por $\{13\}$ el dicho tenientte el dicho vino $\{14\}$ Semette en la carzel a los que le $\{15\}$ an ttenido a su cargo aestetestigo $\{16\}$ Nunca Se le a hecho apremio $\{17\}$ Sobre esta Cobrança Ni lo auisto $\{18\}$ haçer en los demas pueblos Ni $\{19\}$ prender anadie porel valor $\{20\}$ del $d<i c>$ ho Vino y estto es lo que saue $\{21\}$ y lauerdad So cargo del jura $\{22\}$ mentto que tiene fecho enque $\{23\}$ Se afirmo y rratifico $Y$ no firmo $\{24\}$ Por no sauer su merçed lo rru\{25\}brico Y firmo el dicho ynterpre $\{26\}$ tte y que es de edad dequarentay $\{27\}$ Siette años y queno le tocan las $\{28\}$ generales $=$ Joseph de sotomayor $\{29\}$ Anttemi Miguel decanttoral $\{$ h. 259\} [margen superior: e] $\{1\}$ Escriuano de sumagesttad

$\{2\}$ [margen: $\mathrm{t}<\mathrm{es}>\mathrm{t}<\mathrm{igo}>\mid$ Vicente $\mid$ Alonso] En lauilla deguancauelica en siette $\{3\}$ dias del mes de Junio demill y $\{4\}$ seis<cientos> y ochenttay Seis años el $\{5\}$ dicho Señor governador para $\{6\}$ la aueriguaçion Contenida en $\{7\}$ esttos auttos, hiço pareçer ante si avn $\{8\}$ yndio que poryntterpretaçion de Joseph $\{9\}$ de sottomayor Ynterprette Nombrado $\{10\}$ en estta causa dijo llamarse Vicentte $\{11\}$ Alonso y ser natural de la Prouincia $\{12\}$ delos aymaraes delqual por dichayn $\{13\}$ terprettaçion Serreçiuio juramento $\{14\}$ y le hiço por Dios nuestro Señor y auna $\{15\}$ Señal de cruz y prometio decir verdad $\{16\}$ y siendo pregunttado Alttenor del $\{17\}$ autto que baporcaueza dijo que estte $\{18\}$ testigo tiene hecha vna declaraçion $\{19\}$ antte el Docttor Don melchor deco $\{20\}$ tes Peraltta Curay Vicario dela $\{21\}$ Doctrina de Conaica y pe[sobreescrito: i]dio sela lea $\{22\}$ eYo el escriuano Se la ley Y auien $\{23\}$ dola entendido que es verdad que $\{24\}$ Vio en casa de thomas Luis alcalde $\{25\}$ del campo delasiento de acobamba $\{26\}$ dos odres Con vino que trajo delpueblo $\{27\}$ de Vilcabamba parauender alos Yn<dios> $\{28\}$ Por quentta deDon Ju<an> flores $\{h .259 v\}$ [margen superior: e] $\{1\}$ de Valdes tenientte general dela $\{2\}$ prouincia de Angaraes oyo decir al \{3\} Alcalde del campo pagaua adiez pesos $\{4\}$ Cada Votija Y que de niño auisto que $\{5\}$ los ttenienttes queançido de dicha $\{6\}$ prouinçia Como el dicho Don Juan $\{7\}$ flores an embiado Vino 
alpueblo $\{8\}$ de Vilcabamba y alli quando Se $\{9\}$ haçe fiestta enel asientto deacobam $\{10\}$ ba se emuia porelvino quean me $\{11\}$ nestter Sin auer enesto tasa porque \{12\} Nececittan devino para sus fiesttas $\{13\}$ para las misas para Onrras Cassa $\{14\}$ mienttos entierros y nesesidades $\{15\}$ que seles ofreçe $Y$ ademas del vino $\{16\}$ de dichos tthenienttes Otras muchas $\{17\}$ personas ansi Yndios Como españo $\{18\}$ les Venden Vino porsuquenta por $\{19\}$ que ellos lo traen de los Valles y a $\{20\}$ nadie Se aesttorvado el venderlo $\{21\} \mathrm{Y}$ no saue aya violençia ansi en $\{22\}$ rrepartirlo Como en cobrarlo Yesto $\{23\}$ es lo quesaue Y no Otracosa So cargo $\{24\}$ del juramento que tiene fecho $\{25\}$ enqueseafirmo y rratifico $\mathrm{Y}$ no $\{26\}$ firmo por no sauer dijo ser deedad $\{27\}$ demas de treintta años $Y$ que aunque $\{28\}$ es morador end $<$ ic $>$ ho asiento No poreso \{29\} adejado de desir lauerdad su merçed \{h. 260\} [margen superior: e] $\{1\}$ lo rrubrico Y firmo el d<ic $>$ ho Yntter $\{2\}$ prette $=$ Joseph de sottomayor $=\operatorname{an}\{3\}$ tte mi Miguel decanttoral escriuano $\{4\}$ de su magesttad

$\{5\}$ [margen subrayado: $\mathrm{t}<\mathrm{es}>\mathrm{t}<\mathrm{igo}>\mid \mathrm{Ju}<\mathrm{an}>$ cubia] En lauilla deguancauelica en siete $\{6\}$ dias del mes de Junio demill Y $\{7\}$ seiscienttos y ochenttay Seis años el $\{8\}$ $\mathrm{d}<\mathrm{ic}>$ ho Señor governador para la a $\{9\}$ beriguaçion Contenida en esta causa $\{10\}$ hiço parezer antte si avnYndio $\{11\}$ queporYnterpretaçion de Joseph $\{12\}$ de sottomayor Ynterprette nom $\{13\}$ brado dijo llamarse Juan cubia $\{14\}$ y ser natural de la prouinçia devilcas $\{15\}$ del qual por $\mathrm{d}<\mathrm{ic}>$ ha ynterpretaçion $\{16\}$ Serreçiuio juramento y le hizo $\{17\}$ por Dios nuestro Señor y auna se $\{18\}$ ñal de cruz auiendole fecho Pro $\{19\}$ metio deçir verdad y siendo pre $\{20\}$ gunttado al tenor del auto que ba $\{21\}$ por cauesa dijo que este testigo tie $\{22\}$ ne dicho su $\mathrm{d}<\mathrm{ic}>$ ho en raçon delo $\{23\}$ que contiene el $\mathrm{d}<\mathrm{ic}>\mathrm{ho}$ auto antte $\{24\}$ el Docttor Don melchor decottes $\{25\}$ Peraltta Cura y Vicario deconaica $\{26\}$ Y pidio Sela lea y muestre eYo $\{27\}$ el escriuano Se lo ley Y mostre Ya\{28\}uiendole Oydo dijo que enel Sea $\{\mathrm{h} .260 \mathrm{v}\}\{1\}$ firma [margen superior: e] $\mathrm{Y}$ rratifica y que a sido $\operatorname{Cos}\{2\}$ tumbre en aquel paraxe auer $\{3\}$ los thenienttes que an sido de la $\{4\}$ prouinçia delos angaraes em $\{5\}$ biado quatro botijas de Vino $\{6\}$ Cada seis meses al pueblo devilca $\{7\}$ bamba de donde sea distribuido $\{8\}$ en aquel distritto y $\mathrm{d}<\mathrm{ic}>$ ho asiento $\{9\}$ deacobambay alli van por ello $\{10\}$ los Yndios y en aquella Ocaçion $\{11\}$ que trajeron el vino que tiene $\{12\}$ declarado seasia la fiesta de San $\{13\}$ Joseph que fue por carnestolen $\{14\}$ das deeste año y del dicho vino $\{15\}$ Nesesittan para sus entierros $\{16\}$ Casamienttos Onrras y bautismos $\{17\}$ Y otras Necesidades y que el vino $\{18\}$ que corre porquenta del alcalde $\{19\}$ delcampo no les haçe algun apre $\{20\}$ mio sobre que lo gasten y sobre co $\{21\}$ brarlo y que en vn año segastan $\{22\}$ quatro votijas porquenta delos $\{23\}$ thenienttes que ançido y es de la $\{24\}$ dicha prouinçia y todas las perso $\{25\}$ nas que quieren vender Vino $\{26\}$ por juntto $\mathrm{y}$ menudeado lo hazen $\{27\}$ Sin que nadie les estorue y saue $\{$ h. 261\} [margen superior: e] $\{1\}$ Por cosaciertta que menudeado $\{2\}$ Sale decada Votixa diez pesos por lo $\{3\}$ qual Y gasttarse mas vino de lo $\{4\}$ que venden españoles y otras $\{5\}$ personas tiene porcierto No rre $\{6\}$ ciuen los Yndios agrauio porque $\{7\}$ lo mesmo es Comprarlo devna $\{8\}$ partte que de otra y esto es lo que saue $\{9\}$ y lauerdad So cargo del juramento $\{10\}$ que tiene fecho En que seafirmo $\{11\}$ y rratifico y no firmo por no sauer $\{12\}$ Y dijo ser edad demas de cinquenta $\{13\}$ años $Y$ que aunque es Yndio de a $\{14\}$ quel distritto No 
poreso adejado de $\{15\}$ decir lauerdad y su merçed lo $\{16\}$ rrubrico $Y$ firmo el $d<$ ic $>$ ho ynterprete $\{17\}$ Joseph de sottomayor $=$ Anttemi $\{18\}$ Miguel decanttoral escriuano de su $\{19\}$ magestad

$\{20\}$ [margen subrayado: $\mathrm{t}<\mathrm{es}>\mathrm{t}<$ igo $>\mid$ Juan Marca] En lauilla deguancauelica en siete $\{21\}$ dias del mes de febrero demill $\{22\}$ y seisçienttos y ochenta y seis años $\{23\}$ el $\mathrm{d}<\mathrm{ic}>$ ho Señor Governador para $\{24\}$ la dicha aueriguaçion hizo parezer $\{25\}$ anttesi avn Yndio que por ynter\{26\}prettaçion del Ynterprette Nom\{27\}brado dijo llamarse Juan marca $\{28\}$ Y ser natural del pueblo demoya $\{h .261 \mathrm{v}\}$ [margen superior: e] $\{1\}$ dela prouinçia de Angaraes del qual $\{2\}$ Serreçiuio juramento por $\mathrm{d}<\mathrm{ic}>\mathrm{ha}$ ynter\{3\}prettacion y le hiço por Dios nuesttro \{4\} Señor y auna señal de cru y prome $\{5\}$ ttio desir verdad y siendo preguntado $\{6\}$ Alttenor del autto que ba por caueza $\{7\}$ Probeydo por el dicho Señor gover $\{8\}$ nador dijo que estte testigo tiene di $\{9\}$ cho su dicho en rraçon de lo quecon $\{10\}$ tiene en dicho autto antte el docttor $\{11\}$ Don melchor de cotes Peralta Cura $\{12\}$ y Vicario de conaica y pidio Selelea $\{13\}$ eYo el escriuano Sele ley Y mostre $\{14\}$ y auiendole Oido y entendido que es $\{15\}$ Verdad que declaro antte el dicho $\{16\}$ Vicario como $\mathrm{Xp}<$ is $>$ toval rrafael $\{17\}$ Domingo Esteuan fueron alpue $\{18\}$ blo de aCobamba a traer elvino $\{19\}$ queserrepartte enel dicho pueblo $\{20\}$ demoya porquentta de Don Juan $\{21\}$ flores de Valdes teniente general $\{22\}$ de $\mathrm{d}<\mathrm{ic}>$ ha prouinçia que son quattro $\{23\}$ Votixas que sevenden Cada Seis $\{24\}$ meses y a estte testigo Se le dio Vna $\{25\}$ quevendiese y el $d<$ ic $>$ ho Cura pre $\{26\}$ guntto aestte testigo quequantto $\{27\}$ auia Sacado y le dijo su muger $\{28\}$ que siette pesos y medio Yajustando \{h. 262\} [margen superior: e] $\{1\}$ despues la quenta Con la dicha $\mathrm{Su}\{2\}$ muger hallo que ajustauan los $\{3\}$ diez pesos que sepagan a $d<i c>$ ho teniente $\{4\}$ Por cada votija y el auer dicho a $\{5\}$ dicho Cura lo que contiene su dicho $\{6\}$ fue porque la dicha $\mathrm{Su}$ muger $\{7\}$ seadelantto adecir No auia sacado $\{8\}$ Mas que siette pesos y medio y que $\{9\}$ de la pendençia querrefiere el $\{10\}$ dicho $d<i c>$ ho quevbo entre el alcalde $\{11\}$ y rrexidor No saue nada Ni se ha $\{12\}$ llo en ella Ni saue Siestauan em $\{13\}$ briagados O no y el dia Siguiente $\{14\}$ le dieron Noticia deello y enquan $\{15\}$ tto al flette delas mulas que cargan $\{16\}$ el vino y trauajo de Yndios No $\{17\}$ Saue Se les pague cosa alguna $Y$ que $\{18\}$ es costumbre lo traen sin paga $Y$ que $\{19\}$ es verdad que en cada pueblo dela $\{20\}$ Doctrina de conaica se rrepartten qua $\{21\}$ tro votijas cada Seis meses y quelos $\{22\}$ Alcaldes delos pueblos Sobre la Co $\{23\}$ brança azen los apremios querre $\{24\}$ fiere su declaraçion y que la rrepar $\{25\}$ tiçion de dicho vino por los tenientes $\{26\}$ que ançido de dicha prouinçia a sido $\{27\}$ demuchos años aesttapartte $\mathrm{Y}$ no $\tan \{\mathrm{h}$. $262 v\}$ [margen superior: e] $\{1\}$ Solamentte Seauendido elvino $\{2\}$ delos dichos tthenienttes Sino tam $\{3\}$ Vien lo venden y an vendido Otras $\{4\}$ personas y en particular los via $\{5\}$ jeros traen vino por suquenta y es $\{6\}$ tto dijo ser lauerdad So cargo del $\{7\}$ juramentto que tiene fecho en que $\{8\}$ Seafirmo y rratifico y no firmo $\{9\}$ Por no sauer y dijo ser deedad $\{10\}$ detreintta años y que aunque es $\{11\}$ Yndio del $\mathrm{d}<\mathrm{ic}>$ ho pueblo demoya $\{12\}$ No poreso adejado de desir lauerdad $\{13\}$ y lo rrubrico Su merçed y firmo $\{14\}$ el dicho yntterprette $=$ Joseph de $\{15\}$ Sottomayor $=$ Antte mi Miguel $\{16\}$ de canttoral escriuano de su mag<estad> 
\{17\} [margen: $\mathrm{t}<\mathrm{es}>\mathrm{t}<$ igo $>$ | lorenço | Peña] En lauilla deguancauelica en diez $\{18\}$ dias del mes deJunio demill Y $\{19\}$ Seiscienttos y ochentay Seis años $\{20\}$ el d $<$ ic $>$ ho Señor governador para a\{21\}beriguaçion delo conttenido en $\{22\}$ el autto que ba porcaueza proueydo $\{23\}$ porsu merçed hiço pareçer antesi $\{24\}$ avnYndio que porYnterpre $\{25\}$ tacion delYntterprette nombrado $\{25\}$ dijo llamarse Lorenço Peña $Y$ $\{26\}$ que es alcalde del pueblo deMoya $\{27\}$ del qual Su merçed por $\mathrm{d}<\mathrm{ic}>$ haynter $\{28\}$ pretaçion reçiuio juramento y le hizo \{h. 263\} [margen superior: e] $\{1\}$ Por dios y auna Cruz en forma de de $\{2\}$ recho Y prometio decir verdad y sien $\{3\}$ do preguntado al ttenor del dicho auto $=$

$\{4\}$ dijo que este testigo tiene $\mathrm{d}<\mathrm{ic}>$ ho su dicho en $\{5\}$ rracon delo que contiene dicho autto Ypi $\{6\}$ dio Se le lea eYo el escriuano deorden $\{7\}$ del dicho Señor governador Se le Ley $\{8\}$ Y auiendole Oido y entendido por dicha $\{9\}$ Yntterprettaçion dijo que es lo mesmo $\{9\}$ que dijo ydeclaro antte el Docttor $\{10\}$ Don melchor decotes Peraltta Cura $\{11\}$ y Vicario dela Doctrina deconayca $\{12\}$ exceptto en quantto a lapricion que $\{13\}$ rrefiere el dicho dicho porque el the $\{14\}$ nienttegeneral que alpresente es dela $\{15\}$ Prouincia delos angaraes niotraper $\{16\}$ Sona en sulugar digo en su nombre $\{17\}$ No haçen apremios Sobre la cobran $\{18\}$ ça dela platta queproçede del vino $\{19\}$ que rrefiere su declaraçion Y lo que $\{20\}$ pasaes que el alcalde deded $<$ ic $>$ ho pueblo $\{21\}$ para cobrar delos Yndios quean lle\{22\}bado el vino defiado amenacan con $\{23\}$ lacarzel porquepaguen Con puntua $\{24\}$ lidad Y que el rrepartir Vino los $\{25\}$ tenienttes q<ue> an sido de dicha prouincia $\{26\}$ en demuchos años a esta partte $\{27\}$ lo qual le es demucha Comodidad \{h. 263v $\}$ [margen superior: e] $\{1\}$ Porque les sirve para las misas $\{2\}$ que dizen en $d<i c>$ ho pueblo para sus $\{3\}$ bautismos entierros enfermeda $\{4\}$ des $Y$ otras Necesidades que seles $\{5\}$ Ofreçe y en particular para brindar $\{6\}$ alos Yndios que vienen a trauajar $\{7\}$ aesta rreal mina deacogue $=\mathrm{Y}$ aun $\{8\}$ que declaro que de cada Votija Salia $\{9\}$ Siettepesos y medio a hallado por $\{10\}$ Suquentta quesale mas decada Vo\{11\}tija Y que no se acuerda auer decla $\{12\}$ rado en el dicho $\mathrm{d}<\mathrm{ic}>$ ho no salian mas $\{13\}$ quesiette pesos y medio y lo cierto $\{14\}$ es no lo declaro por que silas pulpe $\{15\}$ ras Compran el vino a sietepesos $\{16\}$ Siette y medio y a siette y Cinco $\{17\}$ rreales para lleuar al dicho pue $\{18\}$ blo Y puchulearlo que auian de $\{19\}$ ganar enello y asi es Constantte $\{20\}$ que sale mas menudeado y ttodas $\{21\}$ las personas quequieren vender $\{22\}$ Vino por su quentta lo hacen en $\{23\}$ dicho pueblo $\mathrm{Y}$ sus tterminos $\{24\}$ Sinqueninguna persona ni jus $\{25\}$ tiçia los estorue porque quattro $\{26\}$ Votijas que Comprany da el $\mathrm{d}<\mathrm{ic}>$ ho thenientte general No erabastan $\{27\}$ te para elpastto que tiene el \{h. 264\} [margen superior: e] $\{1\}$ dicho pueblo Y sus conttornos Yesto $\{2\}$ dijo ser lauerdad So cargo del $\{3\}$ juramentto que tiene fecho $\{4\}$ en que seafirmo y rratifico $\{5\}$ No firmo por no sauer dijo ser $\{6\}$ deedad dequarentay siete años $\{7\}$ Y que aunque es tal alcalde No po $\{8\}$ reso a dejado deçir lauerdad $\{9\} \mathrm{Su}$ merçed lo rrubrico y firmo $\{10\}$ el $\mathrm{d}<\mathrm{ic}>$ ho ynterprette $=$ Joseph de $\{11\}$ Sottomaior $=$ Anttemi Miguel $\{12\}$ decanttoral escruiano desu mag<estad>

$\{13\}$ [margen subrayado: $\mathrm{t}<\mathrm{es}>\mathrm{t}<\mathrm{igo}>\mid$ Matheo $\mid$ de segouia] En lauilla deguancauelica en $\{14\}$ quince dias del mes deJunio de $\{15\}$ mill y seiscientos y ochenta y $\{16\}$ Seis 
años el dicho Señor gover $\{17\}$ nador para para la auerigua $\{18\}$ çion delo contenido enel auto $\{19\}$ que ba Por cauesa de esta hizo $\{20\}$ parezer antte si aMatheo de $\operatorname{Se}\{21\}$ gouia minero Morador enela $\{22\}$ sientto desanJoseph de acobam $\{23\}$ ba del qual Su merçed porante $\{24\}$ mi el escriuano rreciuio jura $\{25\}$ mentto y le hizo por Dios nuestro $\{26\}$ Señor y auna señal decruz Ypro\{27\}metio desir Verdad Y siendo pre $\{\mathrm{h}$. $264 \mathrm{v}\}\{1\}$ gunttado [margen superior: e] Sobre lo contenido en $\{2\}$ esttos auttos dijo que este testigo $\{3\}$ Se hallo enel $d<$ ic $>$ ho asiento de $\{4\}$ San Joseph deacobamba en que $\{5\}$ rreçide elcapittan D. Sebastian $\{6\}$ dezenabria minero principal de $\{7\}$ dicho asientto a donde bio que el doctor $\{8\}$ Donmelchor decottes peralta Cura $\{9\}$ de la Doctrina deconaica hizo layn $\{10\}$ formaçion Contenida enestos $a u\langle t o s\rangle\{11\}$ deque fue testigo estteque declara $\{12\} \mathrm{Y}$ le notifico autto Conpena de ex\{13\}Comunion para quetubiese en de $\{14\}$ positto el dicho Odre lleno devino $\{15\}$ y el otro uaçio y que esto es lo quesaue $\{16\}$ y lauerdad So cargo del juramen $\{17\}$ tto quetiene fecho enque seafir $\{18\}$ mo y rratifico y dijo serdeedad $\{19\}$ dequarentay seis años y que $\{20\}$ No letocan las generales Su mer<ced> $\{21\}$ lo rrubrico Y firmo el dicho $\{22\}$ Mattheo de segouia $=$ Mateo $\{23\}$ de Segouia $=$ Anttemi Miguel $\{24\}$ decanttoral escriuano desumag<estad>

$\{25\}$ [margen subrayado: auto] En lauilla deguancauelica en $\{26\}$ Veinttey Çinco dias delmes $\{27\}$ de Junio de seiscientos Yochen $\{28\}$ ttaYseis el dicho Señor Govern<ador> $\{$ h. 265\} [margen superior: e] $\{1\}$ Auiendo Vistto la declaraçion de $\{2\}$ arriua mando que el odre deVino $\{3\}$ y elbaçio que serrefiere enella Se $\{4\}$ entregue aldeposittario general $\{5\}$ de esttauilla para que lo ttenga $\{6\}$ en depositto hastta que sumerçed $\{7\}$ prouea Otra cosa y ansi lo Proueyo $\{8\}$ y rrubrico $=$ ante mi Miguel $\{9\}$ decanttoral escriuanode sumag<estad>

$\{10\}$ [margen: $\mathrm{t}<\mathrm{es}>\mathrm{t}<$ igo $>\mid \mathrm{D}<\mathrm{on}>$ fran $<$ cisco $>\mid$ Cuicapusa] En lauilla deguancauelica en ve $\{11\}$ inttey nueue dias del mes dejunio $\{12\}$ demill y seiscienttos y ochen $\{13\}$ tay seis años el dicho Señor $\{14\}$ governador para aberiguaçion $\{15\}$ delo contenido en el auto que $\{16\}$ bapor caueza hizo parezer ante si $\{17\}$ al maestro decampo Don fran $\langle$ cisco $>\{18\}$ Cuicapusa Caçique prinçipal Y $\{19\}$ governador que fue del rre $\{20\}$ partimiento delos hastos deconaica $\{21\}$ dela prouinçia delos angaraes $\{22\}$ del qual $\mathrm{Su}$ merçed porante $\{23\} \mathrm{mi}$ el esCriuano rreciuio jura $\{24\}$ mentto y le hizo por Dios nuestro $\{25\}$ Señor y auna señal de cruz en $\{26\}$ forma de derecho y prometio de $\{27\}$ çir Verdad y siendo preguntado $\{28\}$ al ttenor del dicho auto $=$ dijo $\{$ h. $265 \mathrm{v}\}$ [margen superior: e] $\{1\}$ que de tiempo ynmemorial aestta $\{2\}$ partte los tenientes generales $\{3\}$ que an sido dela dicha prouin $\{4\}$ çia y el capittan DonJuan flo $\{5\}$ res quealpresentte lo es deella $\{6\}$ an rrepartido enel dicho rre $\{7\}$ partimientto que se Compone $\{8\}$ delos pueblos deconaica Cuenca $\{9\}$ Moya y Vilcabamba Veintey $\{10\}$ quatro Votixas deVino Cada $\{11\}$ Seis meses y seles apagado Y $\{12\}$ paga por cadavna adiez pesos lo $\{13\}$ qual an pagado los yndios de $\{14\}$ los dichos quatro pueblos Contoda $\{15\}$ puntualidad y tiene porçiertto $\{16\}$ estte testigo queno es alos Yndios $\{17\}$ deningun Perjuiçio porque $\{18\}$ Silo fuera Ubieran esclamado $\{19\}$ enel rreal Gouierno y alos $\operatorname{Se}\{20\}$ ñores governadores queansido $\{21\}$ de esttauilla y estte testigo 
Como $\{22\}$ talgovernador y caçique lo $\{23\}$ Ubiera hecho y no ubiera con $\{24\}$ Sentido agrauio Sisintiera que lo $\{25\}$ era anttes leparece y tienepor $\{26\}$ cierto a sido alos yndios devtil y $\{27\}$ Combeniençia porque Vendien $\{$ h. 266$\}\{1\}$ dose [margen superior: e] el vino puchuleado lepareçe $\{2\}$ aestte testigo Se sacaran algo $\{3\}$ mas delos dichos Seis pesos de $\{4\}$ mas deque las personas quelo $\{5\}$ Venden Se balen dela platta $\{6\}$ que sale de $d<i c>$ ho Vino por los seis $\{7\}$ meses que se le da dettermino $\{8\}$ Parauenderlo y los Yndios $\{9\}$ lo ttienen para sus Neçesidades $\{10\}$ entierros honrras y Casami $\{11\}$ enttos y Bautismos y ttodas $\{12\}$ las personas ansi yndios Como $\{13\}$ españoles Sienpre anbenido $\{14\}$ avender elvino que traen en $\{15\}$ Sus rrequas delos llanos $\{16\}$ Sin quenadie Selo ynpida $\{17\}$ y al presentte enel dicho rre $\{18\}$ partimientto y pueblos Se $\{19\}$ esttauendiendo por diferen $\{20\}$ ttes Personas Sin que yn $\{21\}$ tterVenga enello el dicho $\{22\}$ ttenientte general y enel $\{23\}$ tiempo que fue este testtigo $\{24\}$ tal governador y cacique No $\{25\}$ bio que los Yndios Se embria $\{26\}$ gasen Y estto dijo Ser lauerdad \{h. 266v\} [margen superior: e] $\{1\}$ So cargo del juramentto quetiene $\{2\}$ fecho enque se afirmo y rra $\{3\}$ tifico y dijo serdeedad dequa $\{4\}$ renttay tres años poco mas $\mathrm{O}\{5\}$ menos $\mathrm{Y}$ que aunque a sido ttalgo $\{6\}$ vernador Ycaçique No poreso a $\{7\}$ dejado de desir lauerdad Sumer $\{8\}$ çed lo rrubrico y firmo el dicho $\{9\}$ Don françisco $=$ Don françisco $\{10\}$ Cuycapusa $=$ Anttemi, Miguel $\{11\}$ decanttoral escriuano desu $\{12\}$ Magesttad

\{13\} [margen subrayado: $\mathrm{t}<\mathrm{es}>\mathrm{t}<\mathrm{igo}>\mid \mathrm{Ju}<\mathrm{an}>$ guaman] En lauilla deguancauelica en $\{14\}$ Veintte y nueue dias del mes de $\{15\}$ junio demill y seiscientos y o $\{16\}$ chenttay seis años el dicho Señor $\{17\}$ governador para ladicha a $\{18\}$ Veriguaçion hizo parezer an $\{19\}$ ttesi avnyndio quepor yntter $\{20\}$ prettaçion deJoseph de sotomayor $\{21\}$ Yntterprette nombrado dijo $\{22\}$ llamarse Juan guaman alaua $\{23\}$ Y ser natural del pueblo deconaica $\{24\}$ rrepartimientto delos hastos Pro $\{25\}$ vinçia deAngaraes delqual $\{26\}$ Sumerçed poranttemi elescri $\{27\}$ vano rreçiuio Juramentto $\{$ h. 267\} [margen superior: e] $\{1\}$ Y le hizo por Dios nuestro Señor $\{2\}$ y auna Señal de cruz en forma $\{3\}$ dederecho y promettio deciruer $<$ dad $>\{4\}$ y siendo pregunttado alttenor del $\{5\}$ autto que ba por caueza dijo = que $\{6\}$ el capittan Don $\mathrm{Ju}<$ an $>$ flores $\operatorname{deVal}\{7\}$ des ttenientte general delapro $\{8\}$ vinçia de Angaraes aembiado $\{9\}$ alos quatro pueblos del rrepar $\{10\}$ timientto delos hastos veinte $\{11\}$ y quatro Votixas deVino cada $\{12\}$ Seis meses para que sevendiesen $\{13\}$ y puchulearen enellos y selediese $\{14\}$ por cada Votixa diez pesos y por $\{15\}$ lo que toca al dicho pueblo deconaica $\{16\}$ que es vno delos dichos quatro $\{17\}$ pueblos rreçiuio el vino el $\{18\}$ año pasado de seiscientos y $\mathrm{O}\{19\}$ chenttay Çinco por hauer $\{20\}$ Sido alcalde Ordinario deel $\{21\}$ y lo hizo puchulear y salia de cada $\{22\}$ Votixa los dichos diez pesos Sin $\{23\}$ poner Nada desu casa layndia $\{24\}$ que lo vendia y la dicha rrepar\{25\}tiçion de vino an hecho los tenientes $\{26\}$ Sus anttesesores demuchos años $\{27\}$ aesttapartte $Y$ estto aestado en $\{\mathrm{h}$. 267v\} [margen superior: e] \{1\} Costumbre y de dicho Vino No rre $\{2\}$ Sultta ningun agrauio ni per\{3\}juicio a los Yndios de dichos pue\{4\}blos antessi les es demucho Util $\{5\}$ porque Nesesittan deello ansi para $\{6\}$ las misas Como para sus Onrras $\{7\}$ entierros Casamienttos y bau $\{8\}$ tismos y abeçes entran traxine $\{9\}$ ros en los dichos quatro pueblos $\{10\}$ y Venden vino y aguardientte $\{11\}$ Sin auer quien los esttorue 
$\{12\}$ y los Yndios Compran libre $\{13\}$ mentte y Sobre la cobrança $\{14\}$ del vino del dicho ttenientte $\{15\}$ No auistto estte testigo haçer $\{16\}$ ningunos apremios $\mathrm{Ni}$ pri $\{17\}$ ciones porque Con mucha $\mathrm{Su}\{18\}$ ciudad Sevendey sin que $\{19\}$ el dicho tenientte embie $\{20\}$ Por la platta Se la emuian $\{21\}$ Sin auer Sobre estto agrauio $\{22\}$ Ni violençia y esto dijo Ser $\{23\}$ lauerdad So cargo delJura $\{24\}$ mentto que tiene fecho en $\{25\}$ queseafirmo y rratifico $\{26\}$ Y lo firmo y dijo ser deedad $\{27\}$ dequarentta $Y$ nueueaños \{h. 268\} [margen superior: e] $\{1\}$ Y que aunque es yndio de dicho $\{2\}$ pueblo No poreso a dejado dedezir $\{3\}$ laverdad Sumer lo rrubrico $\{4\}$ Juan guaman Alava $=\operatorname{Joseph}\{5\}$ desottomayor $=$ anttemi Mi $\{6\}$ guel de canttoral escruiuano $\{7\}$ desuMagestad

$\{8\}$ [margen: $\mathrm{t}<\mathrm{es}>\mathrm{t}<\mathrm{igo}>\mid$ Martin $\mid$ Pilco] En lauilla deguancauelica en $\{9\}$ Veinttey nueue dias delmes $\{10\}$ deJunio demill y seiscien $\{11\}$ ttos $Y$ ochenttay seis años $\{12\}$ el dicho Señor governador $\{13\}$ para la dicha aueriguaçion $\{14\}$ hizo pareser Ante si avnYndio $\{15\}$ que porYntterprettaçion del $\mathrm{d}<\mathrm{ic}>$ ho $\{16\}$ yntterprette dijo llamarse Mar $\{17\}$ tin pilco y sernatural delpue $\{18\}$ blo de cuenca rrepartimiento $\{19\}$ delos hasttos prouinçia dean $\{20\}$ garaes del qual sumerçed Por $\{21\}$ dicha Yntterpretaçion Reçiuio $\{22\}$ juramentto y le hiço por Dios $\{23\}$ Nuestro Señor y promettio $\{24\}$ desirverdad y siendo pregun $\{25\}$ ttado Alttenor delautto que ba $\{26\}$ Por caueza $=$ Dijo que demu\{h. 268v $\}\{1\}$ chus [margen superior: e] años aestta partte Sea acos $\{2\}$ tumbrado que los thenientes $\{3\}$ generales queançido dela $\mathrm{d}<\mathrm{ic}>\mathrm{ha}\{4\}$ Prouinçia An embiado al $\{5\}$ dicho rrepartimiento que se $\{6\}$ Compone dequatro pueblos $\{7\}$ que son Conaica Cuenca Moya $\{8\}$ y Vilcabamba Veintey quatro $\{9\}$ Votixas deVino Cada seis me $\{10\}$ ses paraque por suquentta se $\{11\}$ Vendiesen y se les diesen adiez $\{12\}$ pesos porcada Votixa y lo mesmo $\{13\}$ a hecho DonJu<an> flores deValdes $\{14\}$ ttenientte general actual lo $\{15\}$ qual no es deningun perjuicio $\{16\}$ a los Yndios anttes le es devtilidad $\{17\}$ el ttener Vino siempre sin obligar $\{18\}$ les ayr a buscarlo aotras partes $\{19\}$ para sus Neçesidades enferme $\{20\}$ dades misas entierros ofrendas $\{21\}$ Onrras bautismos y Casamien $\{22\}$ ttos y de cada Votixa Salen los $\{23\}$ dichos diez pesos y Sobre la cobran $\{24\}$ ca No auistto aya auido agrauio $\{25\} \mathrm{Ni}$ Violençia Ni lavbo siendo es $\{26\}$ tte testigo Alcalde Ordinario $\{27\}$ del dicho pueblo decuenca en $\{$ h. 269\} [margen superior: e] $\{1\}$ quatro Oraçiones y es muy de Or $\{2\}$ dinario en traer harrieros tra $\{3\}$ jineros en los dichos quattro $\{4\}$ pueblos auendervino y lo ven $\{5\}$ den Sin que nadie lo estorue $\{6\}$ y lo mesmo hazen Yndios eYndias $\{7\}$ deestauilla lleuando Vino deella $\{8\}$ Comprandolo alprecio Ordinario $\{9\}$ que es a siettepesos y Medio $\{10\}$ Botixay lo puchulean Por $\{11\}$ ttener alguna ganancia $\{12\}$ yestto es lo que sauey lauerdad $\{13\}$ So cargo del juramentto $\{14\}$ que tiene fecho en que se a $\{15\}$ firmo y rratifico $Y$ lo $\{16\}$ firmo y dijo ser deedad $\{17\}$ deçinquentta años y queaun $\{18\}$ que es Yndio del dicho rre $\{19\}$ partimientto No poreso ade $\{20\}$ jado de desir lauerdad y sumer $\{21\}$ çed lo rrubrico y firmo el $\{22\}$ dicho Yntterprette $=$ Martin $\{23\}$ Pilco $=$ Joseph desottomayor $\{24\}$ Anttemi Miguel decantoral $\{25\}$ escriuano de sumagesttad 
\{26\} [margen: $\mathrm{t}<\mathrm{es}>\mathrm{t}<$ igo $>\mid$ Rodrigo | [**]naica | Palla] Enlauilla deguancauelica en $\{27\}$ VeintteY nueue dias del mes \{h. 269v\} [margen superior: e] $\{1\}$ deJunio demill y seisçienttos Yo $\{2\}$ chenttay Seis años el dicho Señor $\{3\}$ Governador para la dicha aueri $\{4\}$ guaçion hizo parezer Ante si avn $\{5\}$ yndio queporyntterpretaçion del $\{6\}$ yntterprette Nombrado dijo lla $\{7\}$ marse rrodrigo hanaicapalla $\{8\}$ Natural del pueblo devilca $\{9\}$ bamba del rrepartimientto delos $\{10\}$ hasttos prouincia deAngaraes del $\{11\}$ qual Su merçed poranttemi el $\{12\}$ escriuano rreciuio juramento $\{13\}$ y le hiço por Dios nuestro Señor $\{14\}$ y auna Señal decruz y auien $\{15\}$ dole fecho prometio deçir Verdad $\{16\}$ y siendo pregunttado alttenordel $\{17\}$ autto que ba porcaueza = dijo [tachado: 1la] $\{18\}$ que DonJuan flores deValdes $\{19\}$ thenienttegeneral de dicha Pro $\{20\}$ vinçia el tiempo que lo auido deella $\{21\}$ aembrado alos quatro pueblos del $\{22\}$ dicho rrepartimientto paratodos $\{23\}$ ellos Veinttey quatro Votixas $\{24\}$ deVino paraque por suquentta $\{25\}$ Se bendiesen y se le diezen adiez $\{26\}$ pesos por cadaUna y lo mesmo an $\{27\}$ hecho los thenientes Sus antesesores $\{28\}$ Y no rreciuen de esto mas Agrauio \{29\} deYr talvez las Votixas algo peque $\{$ h. 270\}\{1\}ñas [margen superior: e] y no sacan las yndias que lo $\{2\}$ Venden algunas Vezes mas que $\{3\}$ Ocho pesos y medio y nueuey me $\{4\}$ dio que en lo demas le es demucho $\{5\}$ Util y combeniençia porque lo $\{6\}$ tienen para sus Neçesidades y para $\{7\}$ las misas y no les obliga a yrlo $\{8\}$ a buscar a otras partes yes costum $\{9\}$ bre los Yndios delos dichos pueblos $\{10\}$ yr Con sus Mulas para sus granjerias $\{11\}$ ayr atreer vino y ellos y los traxine $\{12\}$ ros españoles lo venden en los $d<i c>$ hos $\{13\}$ quatro pueblos sin quenadie se lo $\{14\}$ esttorue y estte testigo a sido alcalde $\{15\}$ de dicho pueblo deVilcabamba $\{16\}$ y no auistto que Sobre la cobrança $\{17\}$ aya auido ninguna Violençia ni rri $\{18\}$ gor Y que el alcalde aquien Sea $\{19\}$ entregado $d<i c>$ ho Vino arremitido $\{20\}$ los pesos deel Sinque por partte del $\{21\}$ dicho thenientte Se lo pidan y lo $\{22\}$ haçen luego que seacaba devender $\{23\}$ y estto dijo ser lauerdad So cargo $\{24\}$ del juramentto que tiene fecho $\{25\}$ enque seafirmo y rratifico Y lo $\{26\}$ firmo y dijo ser deedad deçin $\{27\}$ quentta años $Y$ que aunque es \{28\} Yndio del dicho rrepartimiento $\{$ h. 270v $\}$ [margen superior: e] $\{1\}$ No poreso adejado de deçir laverdad $\{2\}$ y su merçed lo rrubrico y firmo $\{3\}$ el dicho yntterprette $=$ Joseph $\{4\}$ desottomayor $=$ Rodrigo hanay $\{5\}$ capalla $=$ Anttemi miguel $\{6\}$ de canttoral escriuano de su mag<estad $>\{7\}$ [margen: $\mathrm{t}<\mathrm{es}>\mathrm{t}<$ igo $>\mid$ Sebastian $\mid$ chapa] En lauilla deguancauelica en $\{8\}$ Veinttey nue dias del mes deJunio $\{9\}$ demill y seiscienttos y ochenttaY $\{10\}$ Seis años el dicho Señor governador $\{11\}$ para la dicha averiguaçion hizo $\{12\}$ parezer anttesi avnYndio $\{13\}$ queporyntterprettaçion del dicho $\{14\}$ yntterprette dijo llamarsse $\{15\}$ Sebastian chapa Natural del $\{16\}$ Pueblo deMoya del rreparti $\{17\}$ mientto delos asttos delapro $\{18\}$ vinçia delos angaraes del qual $\{19\} \mathrm{Su}$ merçed por anttemi el es $\{20\}$ Criuano por dichaynterpreta $\{21\}$ çion Serreçiuio juramento $\{22\}$ y le hizo por Dios nuestro Señor $\{23\}$ y auna Señal de cruz y prome $\{24\}$ tio deçir verdad y siendo pre $\{25\}$ gunttado alttenor delacauesa $\{26\}$ deproseso $=$ dijo que los tenien $\{27\}$ ttes queansido dela dichapro\{h. 271\}\{1\}Vinçia [margen superior: e] arrepartido cada Seis $\{2\}$ meses en el dicho pueblo de \{3\} Moya quatro Votijas devino $\{4\}$ paraque sevendan por suquenta $\{5\}$ Cobrando porcadavna adiez pesos $\{6\}$ y lo mesmo a hecho DonJuan $\{7\}$ flores deValdes tenientegeneral $\{8\}$ actual y de dos Votijas que estte $\{9\}$ testigo auendido No an llegado $\{10\}$ a los diez pesos pero faltto 
Poco $\{11\}$ paraellos y es notorio que enesta $\{12\}$ dichauilla Sebenden cada Votixa $\{13\}$ aSiettepesos y medio a todo genero $\{14\}$ depersonas y rrespecto de Aver $\{15\}$ embiado enalgunas Ocaçiones $\{16\}$ Votijas grandes y pequeñas y por $\{17\}$ esa rraçon No sacaria este testi\{18\}go Cabales los dichos diez pesos Yno $\{19\}$ auistto Sobre lacobrança delvino $\{20\}$ Seaya hecho ningun agrauio $\{21\}$ Ni biolençia alos alcaldes nia las $\{22\}$ Yndias quelo an vendido puchule $\{23\}$ ado y por menor y los trajineros $\{24\} \mathrm{y}$ contrattanttes venden sin que $\{25\}$ Nadie Se lo estorue y es devtil $\{26\}$ a los Yndios el que seles rremita $\{27\}$ Por los thenienttes Vino quando $\{28\}$ les dan terminos deseis meses para $\{$ h. 271v $\}$ [margen superior: e] $\{1\}$ Venderlo que elprocedido les Sir $\{2\}$ be para sus grangerias y lo tienen $\{3\}$ para las misas y sus necesidades $\{4\}$ ofrendas y sus fiesttas y estto es $\{5\}$ lo quesaueylauerdad So cargo $\{6\}$ del juramentto que tiene fecho $\{7\}$ enque seafirmo y rratifico $\{8\}$ y no firmo porno sauer y dijo $\{9\}$ Serdeedad detreintta años $\{10\}$ y que aunque es Yndio del dicho $\{11\}$ rreparttimientto No poreso a dejado $\{12\}$ de desir lauerdad y su merced $\{13\}$ lo rrubrico y firmo el dicho yn $\{14\}$ tterprette $=$ Joseph desotomayor $\{15\}$ Antte mi Miguel de canttoral $\{16\}$ Escriuano desu magestad

$\{17\}$ [margen: $\mathrm{t}<\mathrm{es}>\mathrm{t}<\mathrm{igo}>\mid \mathrm{D}<\mathrm{on}>$ thomas $\mid$ Pariona|misa go|vern $<$ ador $>\mid$ delos astos] En lauilla deguancauelica en $\{18\}$ diez y siete dias del mes de julio $\{19\}$ demill y seiscientos y ochenta $\{20\}$ Y seis años el dicho Señor govern<ador> $\{21\}$ para aueriguacion delo contenido $\{22\}$ enel autto que ba porcaueza hiço $\{23\}$ parezer antte si a Don thomas $\{24\}$ Parionamisa Caçique principal $\{25\} \quad Y$ governador del rrepartimi $\{26\}$ entto delos hastos dela pro $\{27\}$ uinçia delos angaraes del $\{27\}$ qual su merçed poranttemi \{h. 272\} [margen superior: e] $\{1\}$ El escriuano porser ladino en $\{2\}$ la lengua Española rreçiuio jura $\{3\}$ mentto y le hizo por Dios nu $\{4\}$ estro Señor y auna Señal de $\{5\}$ Cruz y prometio desir verdad $\{6\}$ y siendo preguntado alte $\{7\}$ nor del dicho autto dijo que $\{8\}$ es verdad que DonJuan flo $\{9\}$ res deValdes tenientte gene $\{10\}$ ral de dicha prouinçia a em $\{11\}$ biado al dicho rrepartimiento $\{12\}$ que se compone dequatro pueblos $\{13\}$ que son Conaica Cuenca moya $\{14\}$ y Vilcabamba Veintey quatro $\{15\}$ Votijas devino cada seis meses $\{16\}$ para que sevendan en dichos pue $\{17\}$ blos puchuleados por menor las $\{18\}$ quales Corren porquentta de $\{19\}$ los Alcaldes y otros ofiçiales $\{20\}$ Y los yndios lo gasttan Volun\{21\}ttariamentte Sin auer enesto $\{22\}$ fuerça anttes es de Comodidad $\{23\}$ y Vien para ellos Porque lo $\{24\}$ tienen para sus Comodidades como $\{25\}$ es Bautismos entierros Y casami $\{26\}$ enttos $Y$ otras cosas que seofreçen $\{27\}$ Y sele da por cada Votixa diez \{28\} Pesos que Puchuleado Saldran \{h. 272v\} [margen superior: e] $\{1\}$ los dichos diez pesos y es muy ordi $\{2\}$ nario en dichos pueblos quequan $\{3\}$ do se asse fiestta en ellos los que qui $\{4\}$ eren lleuan Vino auender y lo $\{5\}$ Venden puchuleado Sin que $\{6\}$ nadie Selo ympida y en todos $\{7\}$ los tenientes generales que an $\{8\}$ sido de dicha prouinçia a $\{9\}$ conoçido estte testigo y Visto em $\{10\}$ biar las dichas Veinttey quatro $\{11\}$ Votixas cada seis meses alos $d<i c>h o s ~\{12\}$ quatro pueblos cobrando decada $\{13\}$ Uno los dichos diez pesos y no saue $\{14\}$ Estte ttestigo que el dicho teniente $\{15\}$ general actual tenga en $d<i c>$ hos $\{16\}$ pueblos mas tratto ni grange $\{17\}$ ria y sila tubiera estte testigo como $\{18\}$ tal governador lo supiera y estto $\{19\}$ es lo que saue y la verdad So cargo $\{20\}$ del 
juramentto que tiene fecho $\{21\}$ en que seafirmo y rratifico y lo $\{22\}$ firmo y dijo ser deedad dequa $\{23\}$ rentta años y que no le tocan las $\{24\}$ generales y su merçed lo rru $\{25\}$ brico $=$ Donthomas Pariona $\{26\}$ misa $=$ Antte mi Miguel de $\{27\}$ Canttoral escriuano de su mag<estad>

\{28\} [margen: Certificaz<ion> $\mid \mathrm{q}<\mathrm{ue}>$ da $\mathrm{D}<\mathrm{on}>$ tho|mas Pariona|misa Gov<ernador> delos | astos] En lauilla deguancauelica en $\{29\}$ diezy siette dias del mes deJulio $\{30\}$ demill Y seiscientos Yochenta \{h. 273\} [margen superior: e] $\{1\}$ Y seis años antte mi el escriuano $\{2\}$ pareçio Don thomas Pariona $\{3\}$ misa Cacique principal $y$ gover $\{4\}$ nador del rrepartimiento de $\{5\}$ los asttos dela prouinçia delos $\{6\}$ angaraes y certifico que en vir $\{7\}$ tud demandatto del Señor $\{8\}$ Docttor DonJuan Luis Lopez $\{9\}$ delconsejo de su mag<estad> alcalde $\{10\}$ decortte mas antiguo dela $R<$ eal $>\{11\}$ audiençia delos rreyes Govern<ador> $\{12\}$ deesta dichauilla correxidor $\{13\}$ y justiçia mayor de dicha Pro $\{14\}$ vinçia a buscado a $\mathrm{Xp}<\mathrm{is}>$ toval $\{15\}$ rrafael Yndio delpueblo $\{16\}$ de Moya de dicho rrepar\{17\}timientto para emuiar\{18\}le aesttauilla aque declara $\{19\}$ sse en estta Causa y No lea $\{20\}$ podido hallar nilos $\operatorname{Yn}\{21\}$ dios aquien le a encargado $\{22\}$ le busqueny no leapodido ha $\{23\}$ llar Ni le conoce ni saue quien $\{24\}$ es ni quien lede rraçon de el y $\{25\}$ por maior le dizen los Yndios \{26\} quevnYndio Nombrado $\{27\} \mathrm{Xp}<$ is $>$ toval Seaausenttado del $\{\mathrm{h} .273 \mathrm{v}\}$ [margen superior: e] $\{1\}$ dicho rrepartimientto y pueblo $\{2\}$ y que se fue asi al balle dejauxa $\{3\}$ No dando rraçon deque sea $X p<$ is $>$ to $\{4\}$ val rrafael elque declaro en $\{5\}$ dicha causa y para que constte $\{6\}$ al dicho Señor governador lo $\{7\}$ certifico ante mi dicho dia $=\{8\}$ Don thomas Pariona misa $\{9\}$ Miguel de canttoral escriuano $\{10\}$ de su mag<estad>

$\{11\}$ [margen subrayado: Autto] En lauilla deguancauelica en $\{12\}$ diez yocho dias del mes de Julio de $\{13\}$ mill y seiscienttos y ochenta $\{14\}$ Y seis años el señor Doctor Don $\{15\}$ Juan Luis Lopez delconsejo de su \{16\} Magesttad su alcalde decortte $\{17\}$ mas antiguo dela rreal audien $\{18\}$ çia delos rreyes Governador $\{19\}$ de estta dicha uilla Su cerro y $\{20\}$ mina $\mathrm{R}<$ eal $>$ deaçogue Correx<idor $>\{21\}$ y justiçia mayor de la Prouin $\{22\}$ çia deAngaraes Alcalde ma\{23\}ior deminas y tenientte de capi $\{24\}$ ttan general en sus distrittos $\{25\}$ auiendo Vistto estos autos dijo $\{26\}$ quemandauay mando Se $\{27\}$ Notifique aDonJuan flo $\{28\}$ res deValdes Alguaçil $m<$ ayor $>\{29\}$ de estauilla $Y$ thenientte $\{$ h. 274$\}$ [margen superior: e] $\{1\}$ general dela prouinçia de $\{2\}$ angaraes Se absttenga de oy $\{3\}$ adelantte de embiar al rrepar\{4\}timientto y Doctrina deconayca $\{5\} \mathrm{Ni}$ otro alguno de dicha Prouinçia $\{6\}$ aVender vino alguno por suquen $\{7\}$ tta en poca Ni en mucha can $\{8\}$ tidad con aperçeuimientto $\{9\}$ queNo hauiendolo Sele ara $\{10\}$ Cargo deello y se le castigara $\{11\}$ en conformidad delas rrea $\{12\}$ les Ordenanças y Çedulas de su $\{13\}$ Magestad que lo prohiuen Y $\{14\}$ fecho Se saque porel presente \{15\} Escruiano Un tanto de estos $\{16\}$ auttos y lo entregue a su mer $\{17\}$ çed para rremitirlo al ex<celentisimo> $\{18\}$ Señor Duque dela Palatta vi $\{19\}$ rrey Y capittan general dees $\{20\}$ ttos rreynos Conel primer chas $\{21\}$ qui y asi lo proueyo Y mando $\{22\}$ Y firmo $=$ DonJuan Luis $\{23\}$ Lopez $=$ antte mi Miguel decan $\{24\}$ toral escriuano de su Magestad - 
$\{25\}$ [margen: $n<$ otificacion>] Enlauilla de guancauelica en $\{26\}$ diez Y nueue deJulio demilly seis<cientos $>\{27\}$ Y ochenttaY seis años Yo el ss<cribano> $\{28\}$ Notifique estte auto alcapp<itan> $\mathrm{D}<\mathrm{on}>\mathrm{Ju}<\mathrm{an}>\{\mathrm{h} .274 \mathrm{v}\}$ [margen superior: e] $\{1\}$ flores deValdes tenientte general $\{2\}$ dela prouinçia delos angaraes en $\{3\}$ Su persona que lo oyo deello doi fee $\{4\}$ y lo firme testigo. Alonso deaguilar $\{5\}$ Miguel de cantoral escriuano $\{6\}$ desuMagesttad

\{7\} Concuerda este traslado con los autos Originales que en $\{8\}$ tregue al $s<$ eñor $>$ $\mathrm{D}<$ octor $>\mathrm{D}<\mathrm{on}>\mathrm{Ju}<\mathrm{an}>$ Luis Lopez del consejo de suma $\{9\}$ gesttad Alcalde decortte mas antiguo de la rr<eal> au $\{10\}$ diençia delos rreyes Govern<ador> de estaui<lla> deguan<cauelica> $\{11\}$ aque me rrefiero Ypara que de ello conste deman $\{12\}$ dami<ento $>$ desu merçed di el presente enla $d<$ ic $>$ haui<lla $>\{13\}$ deGuancau<elica> enveintte y dos dias delmes de Julio \{15\} demill seis<cientos> y ochentay seis años $=$ ba em $\langle$ biado $>=\mathrm{tt}=\mathrm{V}=\mathrm{y}=\{16\}$ mien $=$ Valga $=$ testado $=$ pueblo $=\mathrm{m}$ lo $=\operatorname{mostrado}\{17\}[$ mano 2] $\mathrm{Y}$ Enfee deello hize $\operatorname{mi}\{18\}$ signo $\{19\}$ Entestim<onio> deverdad

$\{20\}$ Miguel decantoral $\{21\}$ scriu<ano> de sumag<estad> 